\title{
Asynchronous Video and the Development of Instructor Social Presence and Student Engagement
}

Kayla E. Collins

University of St. Augustine for Health Sciences

DOI: https://doi.org/10.46409/sr.XNWF2435

Follow this and additional works at: https://soar.usa.edu/dissertations

Part of the Higher Education Commons, and the Online and Distance Education Commons

\section{Recommended Citation}

Collins, K. E. (2017). Asynchronous Video and the Development of Instructor Social Presence and Student Engagement. [Doctoral project, University of St Augustine for Health Sciences]. SOAR @ USA: Student Dissertations Collection. https://doi.org/10.46409/sr.XNWF2435 
ASYNCHRONOUS VIDEO AND THE DEVELOPMENT OF

INSTRUCTOR SOCIAL PRESENCE AND STUDENT ENGAGEMENT

\author{
A Dissertation Presented to \\ The Doctorate of Education Program \\ University of St. Augustine for Health Sciences \\ St. Augustine, Florida \\ In Partial Fulfillment \\ of the Requirements for the Degree \\ Doctor of Education \\ by \\ Kayla E. Collins \\ April, 2017
}




\author{
WE, THE UNDERSIGNED MEMBERS OF THE COMMITTEE, HAVE APPROVED \\ THIS DISSERTATION IN PARTIAL FULFILLMENT OF THE REQUIREMENTS \\ FOR THE DEGREE \\ DOCTOR OF EDUCATION
}

\title{
ASYNCHRONOUS VIDEO AND THE DEVELOPMENT OF INSTRUCTOR SOCIAL PRESENCE AND STUDENT ENGAGEMENT
}

By

Kayla E. Collins

COMMITTEE MEMBERS

\begin{tabular}{|c|c|c|}
\hline $\begin{array}{l}\text { Dr. Shannon } \\
\text { Groff }\end{array}$ & 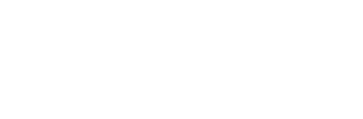 & $4 / 14 / 2017$ \\
\hline Shannon Groff, $\mathrm{P}$ & Chair) & Date \\
\hline
\end{tabular}

Dr. Cindy Mathena 


\section{ACCEPTED AND APPROVED ON BEHALF OF THE UNIVERSITY}

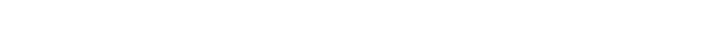 \\ Augustine for Health Science, ou=Dean of Post \\ Date: 2017.05.19 15:30:20 -04'00'}

Cindy Mathena, PhD, OTR/L

Dean of Post Professional Studies, University of Saint Augustine for Health Sciences

University of Saint Augustine for Health Sciences, Saint Augustine FL

April 2017

COMMITTEE MEMBERS

Committee Chair: Shannon Groff, PhD

Contributing Faculty

University of Saint Augustine for Health Sciences

Committee Member: Cindy Mathena, PhD, OTR/L

Dean of Post Professional Studies

University of Saint Augustine for Health Sciences 


\begin{abstract}
Enrollment in online learning continues to grow in the higher education sector, along with persistent goals dedicated to achieving better student outcomes and lowering attrition rates. Improved student engagement has been shown to possibly reduce attrition rates through a greater sense of connectedness and decreased feelings of isolation among online learners. Through the development of a classroom community, the online learner may feel supported and engage more often in the learning process.
\end{abstract}

The instructor plays a major role in the development of the classroom community. Instructor social presence may be the most important factor in building the relationships that foster learning and retention. Through communication, the instructor conveys the necessary immediacy behaviors required to cultivate these interpersonal relationships. Discovering methodology that can facilitate the development of instructor social presence and foster student engagement is necessary for improving online learning outcomes and retention.

With improved technology that allows for enhanced communication in online classrooms, the use of asynchronous video may be an effective way to improve instructor social presence and student engagement. This quasi-experimental design aimed to determine whether asynchronous video or text-based communication increased students' perceptions of instructor social presence and student engagement in an online graduate classroom. After analyzing the data, significance was found for student engagement based on the number of discussion posts, $\mathrm{p}=.003$, and length of discussion posts, $\mathrm{p}=.012$. Students in the group who received text-based communication demonstrated increased student engagement in voluntary discussion boards as opposed to students in the group who received asynchronous video. There was no significant difference found for instructor social presence between the two groups, $p=.136$. The participants of the study were students enrolled in two sections of an online Masters of Occupational Therapy 
foundation course during the spring of 2017. All participants attended the University of St. Augustine for Health Sciences. 


\section{Acknowledgements}

My dissertation would not have been possible without the guidance and support of my committee members, colleagues, and family. I would like to express my gratitude to my committee chair, Dr. Shannon Groff, for her patience and dedication. Her persistence, positive attitude, and support kept me grounded. I could not have accomplished this dissertation without her encouragement. I would also like to thank my committee member, Dr. Cindy Mathena, who has been an inspiration and a mentor throughout my studies at the University of St. Augustine. Thank you to all my colleagues who were willing to listen, counsel, and reassure me during this time. A special thanks to Dr. Prerna Poojary-Mazzotta, Dr. Anne Hull, Dr. Julie Watson, and Dr. William Ganza. My children, Madilyn and Cooper Collins, your smiles and inquisitive nature inspire me. Last but certainly not least, I would like to thank my husband, Chris Collins, for his endless support and understanding as I pursued my educational goals. 


\section{Table of Contents}

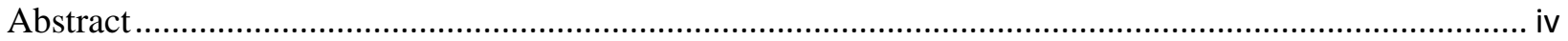

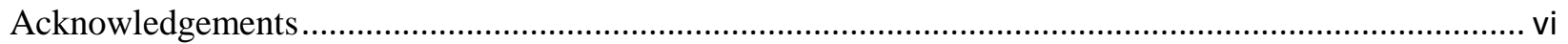

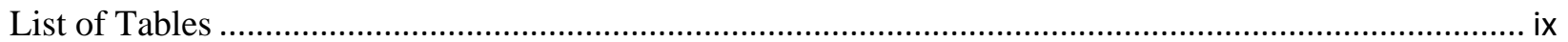

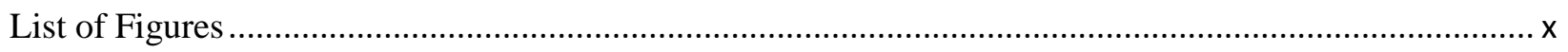

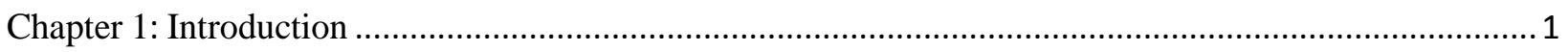

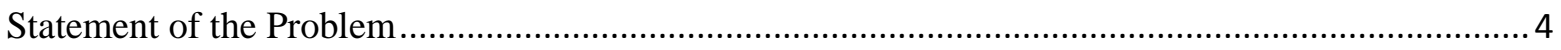

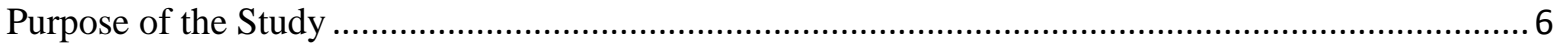

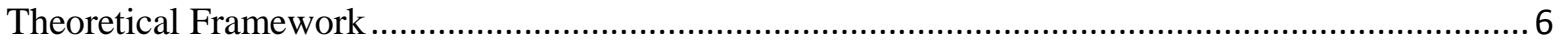

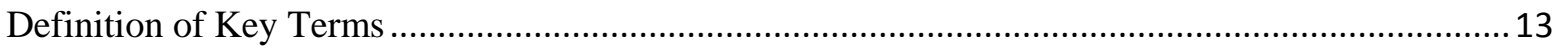

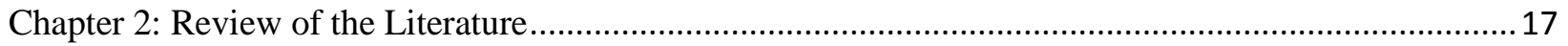

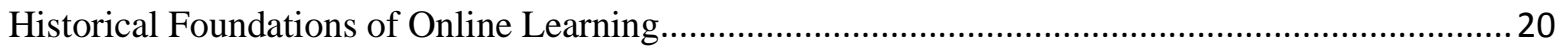

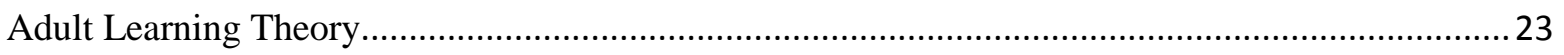

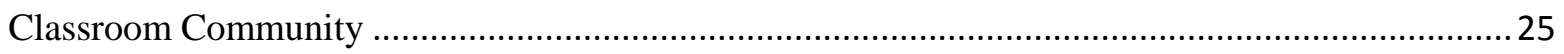

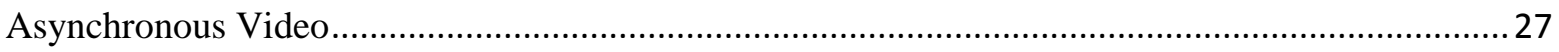

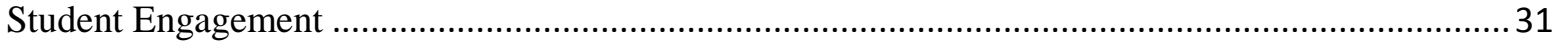

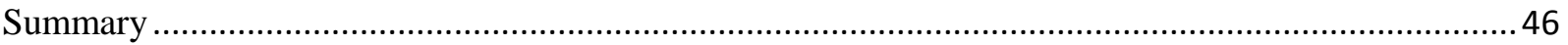

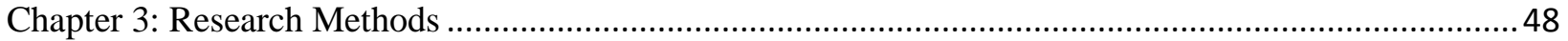

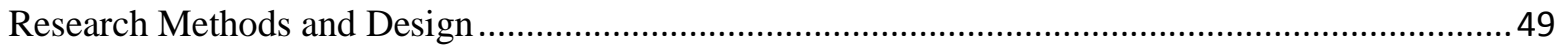

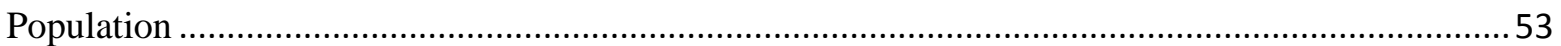

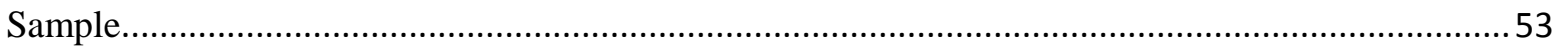

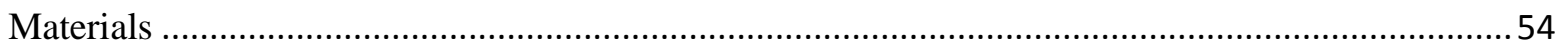

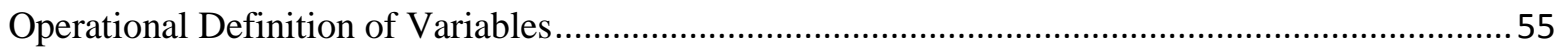

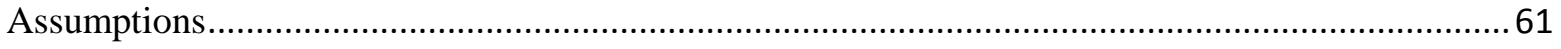

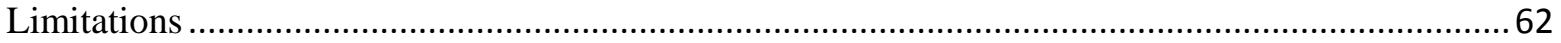

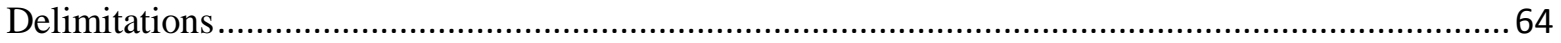

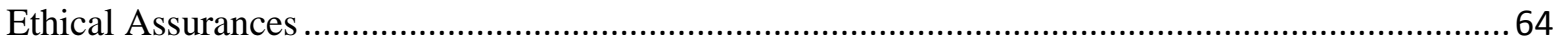

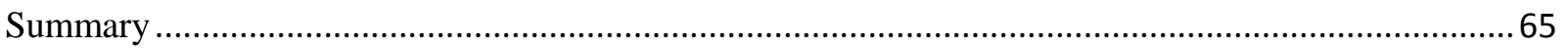

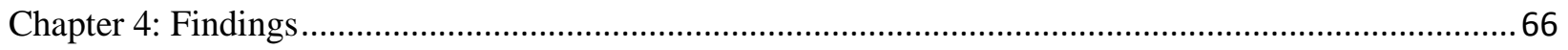

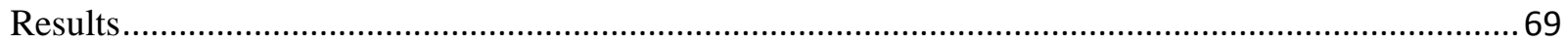

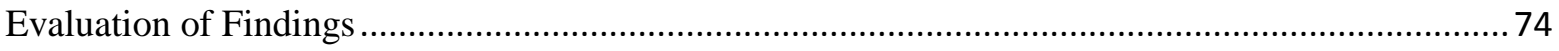

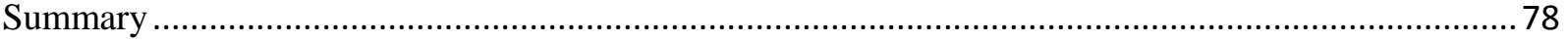

Chapter 5: Implications, Recommendations and Conclusions ................................................................ 79 


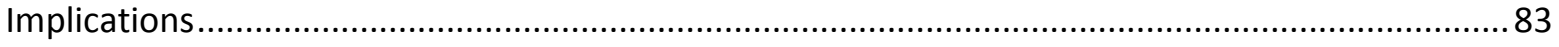

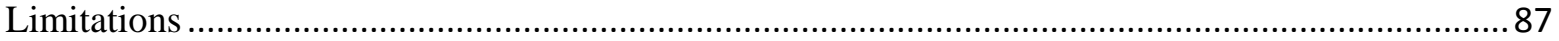

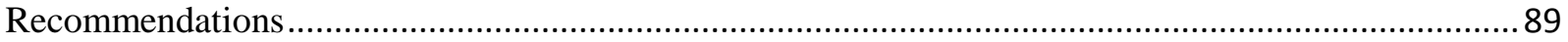

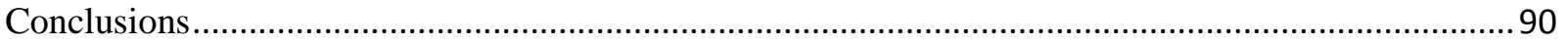

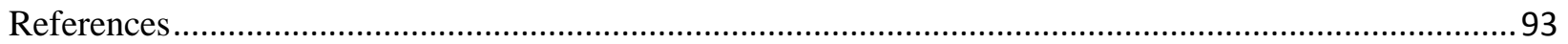

Appendix A: Permission Granting Access to University Students and Materials .................................. 105

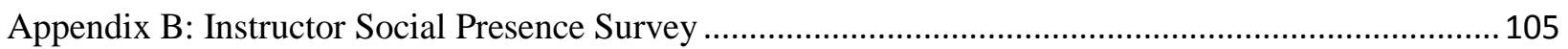

Appendix C: University of St. Augustine Institutional Review Board Approval ................................... 107

Appendix D: Weekly Announcement Structural Outline ................................................................... 108 


\section{List of Tables}

Table 1. Summative Analysis of Univariate Statistics.......................................................70

Table 2. Kruskal-Wallis Summative Analysis ............................................................... 70

Table 3. MANOVA Results for Dependent Variables Based on the Type of Communication and Number of Discussion Posts

Table 4. MANOVA Results for Dependent Variables Based on the Type of Communication and Length of Discussion Posts..... 


\section{List of Figures}

Figure 1. Representation of the Community of Inquiry framework, indicating the educational experience as the intersection of cognitive, teaching, and social presences, which are influenced externally by the communication medium..........................................................................

Figure 2. Kahu's (2013) framework explains the influence of structural and psychosocial antecedents on student engagement and the consequences of the development of engagement...10 


\section{Chapter 1: Introduction}

Online learning is an increasingly popular mode of delivery for students in today's higher education landscape. More than $25 \%$ of higher education students participate in at least one online course, and despite an overall decrease in higher education enrollments, online education enrollments continue to grow (Allen, Seaman, Poulin, \& Straut, 2016). Regardless of evidence that student performance outcomes are similar between face-to-face and online education delivery, perceptions of the effectiveness of online learning have recently declined (Allen et al., 2016). Faculty remain skeptical about the usefulness of online education for providing quality learning experiences (Allen et al., 2016). Online learning creates an atmosphere which allows for greater access to education by reducing the barriers of time and place, but it also changes the ability of peers and instructors to support each other through face-to-face interactions (O'Shea, Stone, \& Delahunty, 2015). Text-based communication and the typically asynchronous nature of online learning can create feelings of disconnect or a transactional distance between students and instructors (Byrd, 2016; Estes, 2016). This transactional distance has been shown to reduce student engagement, which is a major predictor of student retention, and an area of concern for higher education institutions that offer online courses (Byrd, 2016; Estes, 2016).

Higher education institutions struggle to improve student retention as student enrollment grows and the demand for positive student outcomes increase. Specifically, online education reportedly has higher attrition rates than traditional face-to-face classes (Xu \& Jaggars, 2014). Allen et al. (2016) found that administrators of higher education institutions felt that student attrition in online courses was a significantly larger problem than in face-to-face courses. Students chose to drop out of courses for a variety of reasons, though in the online learning 
environment, feelings of isolation caused by a lack of interaction with others, was a primary cause (Ali \& Smith, 2015; Bowers \& Kumar, 2015; McMahon, 2013).

Feelings of isolation seem to pervade online learning and may be caused by a lack of interpersonal relationships with peers and faculty (Bowers \& Kumar, 2015; McMahon, 2013). This lack of relationships leads to a perceived disconnection from the learning community (Bowers \& Kumar, 2015; McMahon, 2013). Weiss (2000) asserted that through interpersonal relationships, the online learning environment becomes humanized, and allows students to feel they are connecting with real people behind the computer screen. Establishing humanity in an online course may help students feel committed to their learning and encourages them to engage in classroom activities (Weiss, 2000). Student engagement may be the most important method for increasing student retention in online courses (Angelino, Williams, \& Natvig, 2007; Tinto, 1997).

While challenging to define, student engagement may be thought of as the cognitive, emotional, and behavioral effort students put into a course, as measured by their time, participation, feelings, and communication with instructors and peers (Dixson, 2015). Engagement requires students to take an active role in the learning process and be deliberate in the development of knowledge (Pittaway, 2012). Understanding student engagement is paramount as new educational policies push more people to enter secondary education. At the same time, millions of students have dropped out of programs or require significant remediation (Lawson \& Lawson, 2013).

The important role of the instructor in facilitating and encouraging student engagement must be addressed when developing an online course. Chickering and Gamson (1987) established contact between students and faculty as one of the main principles for good practice 
in higher education. The social interaction between instructors and students, developed by instructor social presence, creates a meaningful sense of classroom community which leads to improved engagement and decreased attrition (Bowers \& Kumar, 2015). Instructor social presence may increase student engagement in the classroom through fostering group cohesion, affective expression, and open communication, as described in the Community of Inquiry (COI) framework (Garrison, Anderson, \& Archer, 2000). To positively impact engagement and retention issues, it is essential to understand the methods for improving instructor social presence in an online classroom.

Through improvements in technology, such as the use of video, instructor social presence may be easier to convey than in the earlier years of online education delivery. Using text-based communication, instructors may rely on the use of emoticons, humor, and addressing students by name to improve their perceptions of instructor social presence (Garrison et al., 2000). Verbal forms of teacher immediacy behaviors, such as facial expressions, body language, and vocal inflections, are not easily conveyed through text-based communication, yet they are essential for motivating students to participate (Estepp \& Roberts, 2015; Mehrabian, 1971). Video technology may be an essential tool for developing students' perceptions of instructor social presence because of the opportunity for instructors to convey both verbal and non-verbal instructor immediacy behaviors (Borup, Graham, \& Velasquez, 2011; Griffiths \& Graham, 2009; Ice, Curtis, Phillips, \& Wells, 2007). As online learning grows in popularity, it is important to understand the ability of asynchronous video technology to improve instructor social presence, which may lead to improved student engagement and retention. 


\section{Statement of the Problem}

The problem this study addressed is the challenge of using educational technology to improve student engagement in an online course. Engaging students in online courses has been shown to improve student retention, which is a major area of concern for online learning programs (Allen \& Seaman, 2014; Atchley, Wingenbach, \& Akers, 2013; Pazzaglia, Clements, Lavigne, \& Stafford, 2016). Institutions are developing more online learning opportunities, and students are gravitating towards those options for many of their educational needs, despite continued concern about retention (Allen \& Seaman, 2014; Xu \& Jaggars, 2014). Online courses tend to be attractive options for non-traditional students who may not respond to the same teaching techniques as traditional students (O'Shea et al., 2015; Tilley, 2014). Studies focused on improving student outcomes in traditional classrooms cannot necessarily be translated into successful teaching techniques in the online class (Ortagus, 2017). Not only are the social interactions in online learning varied due to affordances in communication technology, but the students themselves are typically different than students in traditional classes. Students who choose to enroll in online courses are usually older and have non-academic commitments such as work or family (O’Shea et al., 2015; Tilley, 2014). In post-secondary education, online students may be returning to an academic role after several years of being outside the educational system. (O’Shea et al., 2015; Tilley, 2014). These students are termed non-traditional, and represent a rapidly growing population of students pursuing post-secondary education (Tilley, 2014). Understanding mechanisms to improve student retention in online classrooms and support the growing population of non-traditional students, is important for improving outcomes in online education. 
Institutions need to understand factors that contribute to student retention and how to improve the aspects of online learning that impact student success, including student engagement (Dixson, 2010, 2015; Tinto, 1997). Promoting student engagement is challenging for educators without the natural social interaction which occurs in traditional classroom settings (Borup, West, Thomas, \& Graham, 2014; Estepp \& Roberts, 2015; Tichavsky et al., 2015). The social interaction between the student and instructor may be the most important factor influencing student engagement (Ma, Han, Yang, \& Cheng, 2015; Zepke, Leach, \& Butler, 2010). It has been suggested that instructor social presence may be a significant predictor of improved student engagement through its influence on the development of the instructor-student relationship (Ma et al., 2015; Phirangee et al., 2016).

Prior research on the role of the instructor in promoting student engagement focused on the development of a sense of community, methods for communicating with students, and the general importance of communication between instructors and students (Bowers \& Kumar, 2015; Byrd, 2016; King, 2014; Tomas, Lasen, Field, \& Skamp, 2015). A substantial correlation between the instructor's role and student engagement was found (Byrd, 2016; Glazier, 2016; Phirangee et al., 2016). Several researchers developed the assumption that this correlation was a result of the instructor's social presence. However, instructor social presence as the predominate construct influencing student engagement has not been formally researched (Bowers \& Kumar, 2015; Glazier, 2016; K. Swan \& Shih, 2005). Research on the role of the instructor in developing student engagement has been mostly qualitative-based, with little quantitative data to support or refute qualitative findings that indicate a relationship between the two constructs (Byrd, 2016; Glazier, 2016; K. Swan \& Shih, 2005). Methods for utilizing technology, such as asynchronous video, used to increase the student's perceptions of instructor social presence and student 
engagement, has been limited as well (Borup et al., 2014; Glazier, 2016; Kushnir \& Berry, 2014). Therefore, this research study addressed the effect of asynchronous video versus textbased communication on students' perceptions of instructor social presence and the impact on student engagement in the online learning environment.

\section{Purpose of the Study}

As stated previously, the purpose of this quasi-experimental quantitative study was to determine the effect of asynchronous video, as compared to text-based communication, on student perceptions of instructor social presence and student engagement in an online graduate course. Student retention in online classes is a growing concern in higher education, and increasing student engagement may be a way to address this problem (Allen et al., 2016). Through facilitation of instructor social presence using asynchronous video and text-based communication in an online graduate course, instructors may be able to increase student engagement and thus reduce attrition.

The University of St. Augustine for Health Sciences is in the process of converting many of its traditional classroom courses into blended or fully online classes. This study may help instructors and institutions who conduct graduate courses in an online environment increase student engagement, and reduce issues of retention, by understanding the utility of asynchronous video or text-based communication to alter student's perceptions of instructor social presence.

\section{Theoretical Framework}

Instructor social presence is a relatively new construct based on the Community of Inquiry (COI) framework originally described by Garrison, Anderson, and Archer (2000), which indicated that social, cognitive and teaching presence were essential components of the educational experience (see Figure 1). 


\section{Community of Inquiry}

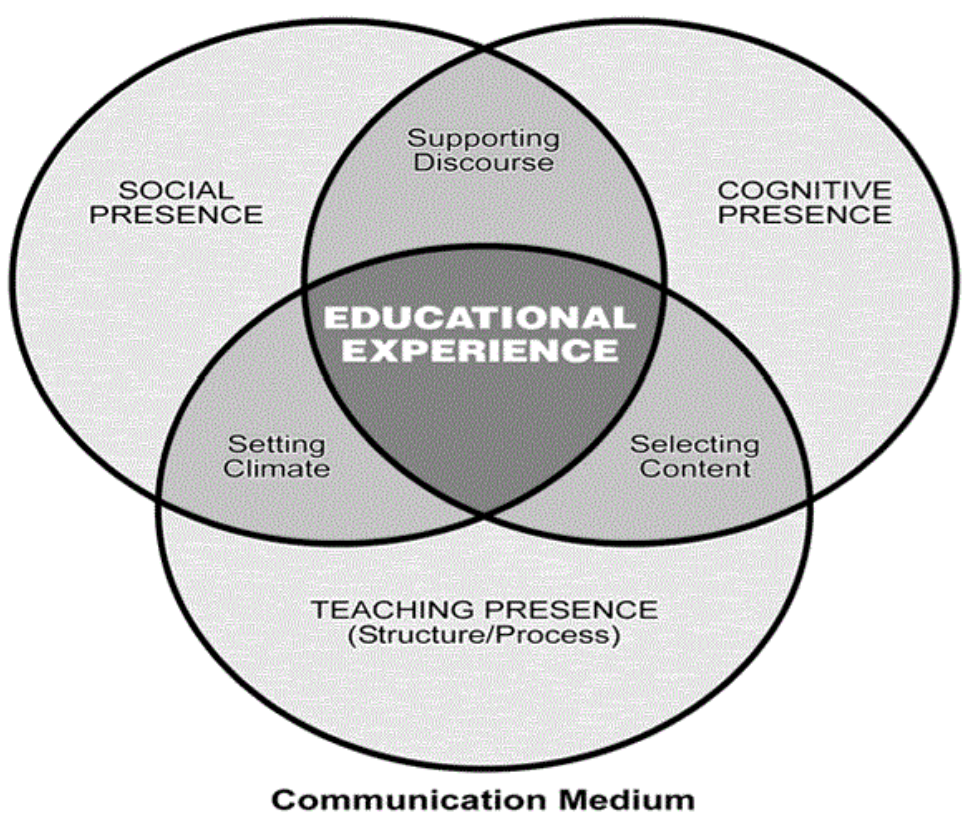

Figure 1. Representation of the Community of Inquiry framework, indicating the educational experience as the intersection of cognitive, teaching, and social presences, which are influenced externally by the communication medium. Adapted from "The First Decade of the Community of Inquiry Framework: A Retrospective," by D. R. Garrison, T. Anderson, and W. Archer, 2010, Internet and Higher Education, 13, p. 6. Copyright 2009 by Elsevier Inc. Reprinted with permission.

Teaching presence and social presence are descriptions of two pieces of an educational environment that interact with one another to enable learning to occur by setting the climate for discourse and interpersonal communication (Garrison et al., 2000). Within this framework, the roles of the teachers and students are outlined as interconnected components which, along with the communication medium, are important to the overall success of the learning experience.

Social presence refers to the ability of students and teachers to be perceived as "real" by demonstrating their personalities and other characteristics to the community (Garrison et al., 2000). Social presence builds on the collaborative constructivist learning theory, which also posits that learning occurs when there is collaboration and social interaction to facilitate the 
building of knowledge (Swan, Garrison, \& Richardson, 2009). Short, Williams, and Christie (1976) originally defined social presence as "the degree of salience of the other person in the interaction and the consequent salience of the interpersonal relationships" (p.65). The authors believed social presence was a direct result of the quality of communication, and that the perceived level of social presence would vary depending on the media used. The quality of communication and degree of social presence depended largely on whether immediacy behaviors could be conveyed appropriately. The ability of others to perceive non-verbal immediacy behaviors varies according to the mode of communication used, including text and video, and is critical to the development of interpersonal relationships between the instructor and student (Borup et al., 2011; Borup, West, \& Graham, 2012).

Teaching presence was described by Garrison et al. (2000) as including "instructional management, building understanding, and direct instruction" (p. 24) that occurs within a course. The role of teaching presence in facilitating discourse is noted in the literature. Teaching must also include a high level of social presence in order to have the intended effect on student learning (Garrison et al., 2000; Lowenthal, 2016). The role of teaching presence is to encourage, acknowledge, reinforce and guide the educational process through reflection, assessment, and feedback. Some examples of teaching presence include structuring content, sharing personal values, and answering questions (Garrison et al., 2000). In an online course, clear communication and prompt feedback from instructors are valuable components of teaching presence that increase student satisfaction and improve student outcomes (Richardson et al., 2015).

While social and teaching presence were initially determined to be the responsibility of both the learner and the teacher (Rourke, Anderson, Garrison, \& Archer, 2007), the focus of 
research has mainly been on peer social presence and instructor teaching presence. There is a clear indication that the instructor's role in social presence is important to the learning experience and that the teaching presence alone does not fully describe the student-teacher interaction that creates student engagement (Lowenthal, 2016; Pollard, Minor, \& Swanson, 2014; K. Swan et al., 2009). The construct of instructor social presence has been developed to describe the overlap between teaching presence and social presence that is essential to online learning (Lowenthal, 2016; Richardson et al., 2015). Instructor social presence includes instructor attributes conveyed in a course that go beyond the structural organization and execution of the content (Sheridan \& Kelly, 2010). This includes the way an instructor "positions him/herself socially and pedagogically in an online community" (Richardson et al., 2015, p. 259). Instructor social presence may significantly alter the student's experience of the course, which then impacts their engagement and their likelihood to persist.

Kahu's (2013) framework of student engagement also points to the importance of instructor social presence as a predicting factor in the development of student engagement (see Figure. 2). Within his framework, Kahu (2013) explained the complicated nature of student engagement as it manifests itself in affective, cognitive, and behavioral ways within a course. Significant for this study is the emphasis on interaction and participation as behavioral components of engagement, as well as the affective manifestations of interest and enthusiasm. Previous studies have looked at the amount or depth (interaction and participation) of discussion board posts to measure student engagement, but have not done so using voluntary discussions (Draus, Curran, \& Trempus, 2014). Voluntary discussions require students to go beyond the requirements of the class, and in turn, allow them to demonstrate interest and enthusiasm for the course. 


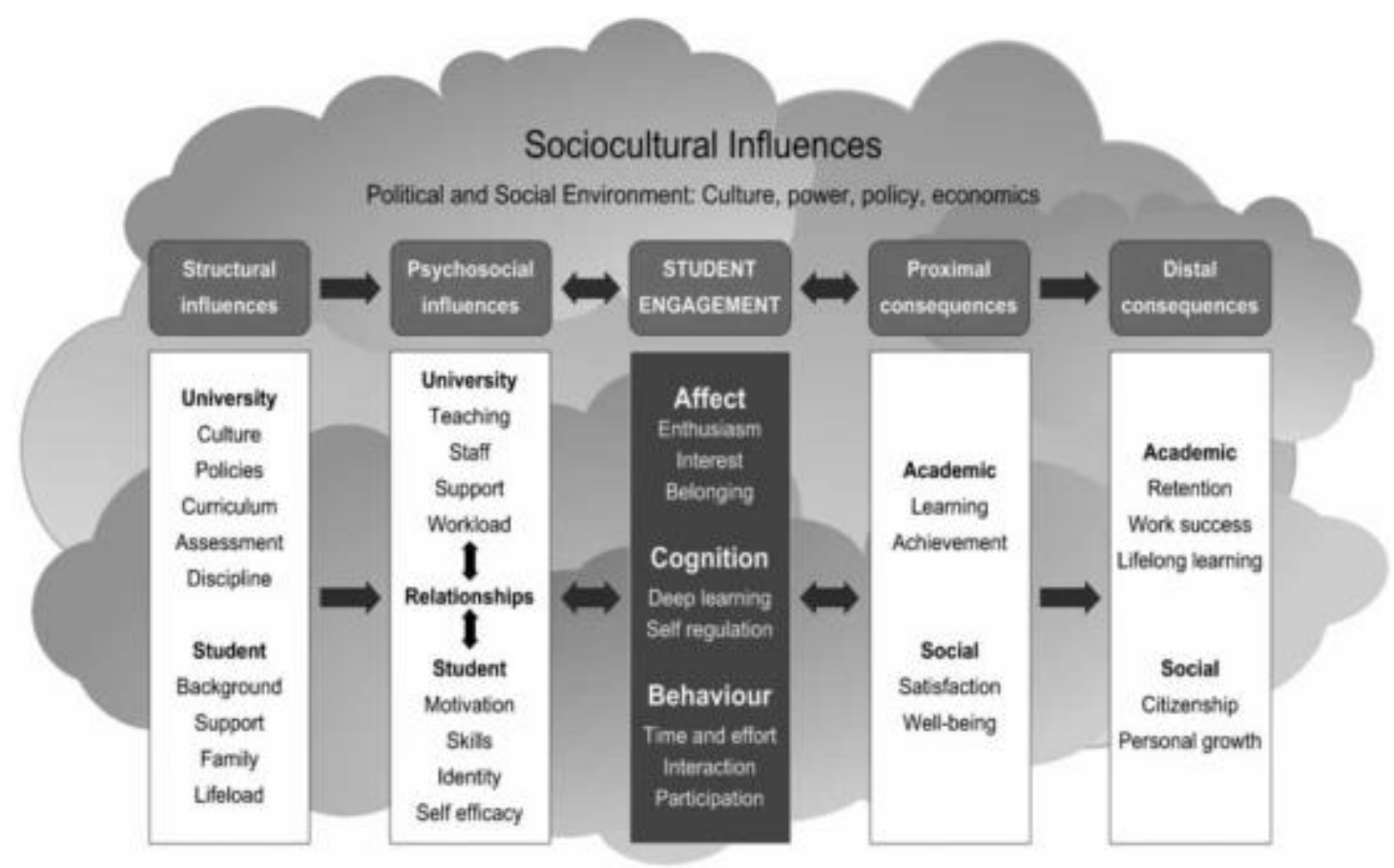

Figure 2. Kahu's (2013) framework explains the influence of structural and psychosocial antecedents on student engagement and the consequences of the development of engagement. This framework provides a basis for understanding the influence of relationships on the development of affective, cognitive, and behavioral engagement, as well as the ultimate consequence of student retention. Adapted from "Framing Student Engagement in Higher Education," by E. Kahu, 2013, Studies in Higher Education, 38(5), p. 766. Copyright 2013 by Taylor and Francis Group. Reprinted with permission.

Kahu's (2013) framework illustrated the relationship between the communication medium (structural influences), the instructor-student relationship (psychosocial influences) and the effect of both on student engagement. The framework explored the consequences of student engagement which included retention as a distant result. This model implied a direct link between communication medium, instructor-student relationships, and student engagement, based on available literature. However, this relationship has not been explicitly researched and 
the role of instructor social presence on the development of the instructor-student relationship has not been fully addressed (Kahu, 2013).

\section{Research Questions:}

The purpose of this quasi-experimental quantitative study was to determine the effect of asynchronous video as compared to text-based communication on student's perceptions of instructor social presence and student engagement in an online graduate course. Non-directional hypotheses were used because there is a lack of consensus and quantitative support in the literature for assuming a relationship between the variables that were studied.

RQ1: Does instructor use of asynchronous video change students' perceptions of instructor social presence in an online occupational therapy course?

RQ2: Does instructor use of asynchronous video change student engagement in an online occupational therapy course?

\section{Hypotheses}

H10 There is no statistically significant difference in the level of perceived instructor social presence based on instructor use of asynchronous video.

H1 a There is a statistically significant difference in the level of perceived instructor social presence based on instructor use of asynchronous video.

H2 0 There is no statistically significant difference in the level of student engagement based on instructor use of asynchronous video.

H2a There is a statistically significant difference in the level of student engagement based on instructor use of asynchronous video.

\section{Organization of the Remainder of the Study}


This quasi-experimental, quantitative study examined the effects of asynchronous video versus text-based communication on student's perceived instructor social presence and student engagement in an online course. Prior literature exploring the effects of video technology on the perceptions of instructor social presence is described. The impact of instructor social presence on the development of the instructor-student relationship and how those relationships impact student engagement is illustrated through existing literature. The significance of student engagement on the long-term outcomes of online student success, such as retention, is also defined.

This study was conducted during the spring 2017 term at the University of St. Augustine for Health Sciences, using two sections of a first term Masters of Occupational Therapy course. Participants were enrolled in their first term of study in the Masters of Occupational Therapy program, and were automatically registered in a section of the OCT 5140-Domain of Occupational Therapy course. Registration was based on the students' enrollment status as a campus (Group A) or Flex program (Group B) student. The specific details of the implementation of the research methodology is explained, using current literature and data to support the study methods. Data was analyzed using appropriate statistical analysis for a between-subjects design through SPSS software. Post-hoc tests were conducted as necessary. Conclusions and suggestions for further research were made based on the research results. Implications for application in an educational setting was addressed. The researcher was granted permission to perform this study by the University of St. Augustine for Health Sciences IRB committee (see Appendix A). 


\section{Definition of Key Terms}

The key terms in the present study are related to the field of online higher education. They refer specifically to the use of different communication mediums for enhancing instructor social presence and student engagement.

Face-to-Face Learning. A format of education delivery that allows for direct contact between the instructor and students, with either no online learning or technology enhanced learning that does not reduce face-to-face contact time (Graham, Woodfield, \& Buckley Harrison, 2013).

Online Learning. Also termed distance learning and e-Learning, online learning can be either completely online with no face-to-face educational delivery, or mostly online with occasional face-to-face contact employed for select activities (Graham et al., 2013)

Blended Learning. A format of education delivery that allows for a combination of online and traditional (face-to-face) learning (University of St. Augustine, 2016b). Blended learning programs require a reduction in face-to-face contact time in lieu of increased online contact time (Graham et al., 2013).

Flex Program. One of the program delivery options for the Masters of Occupational Therapy degree, which conducts at least $50 \%$ of a student's coursework online, with most faceto-face meetings reserved for lab activities on weekends (University of St. Augustine, 2016a)

Campus Program. One of the program delivery options for the Masters of Occupational Therapy degree, which includes online and face-to-face instruction, with "some portions of the course content presented through a variety of interactive online activities and augmented by inclass discussions" (University of St. Augustine, 2016a, p. 79). 
Asynchronous Video. A type of technology that utilizes visual and auditory capturing to create a video which can be displayed to others at a separate date and time and has the potential to convey both verbal and non-verbal immediacy behaviors, similar to a traditional course (Borup et al., 2011; Short, Williams, \& Christie, 1976).

Immediacy Behaviors. The verbal and non-verbal methods of communication used to create connections between people and form interpersonal interactions (Mehrabian, 1971). In a classroom, instructors demonstrating these behaviors can create a closeness between the instructor and the student (Borup et al., 2011). Immediacy behaviors can include eye contact, gestures, the use of humor, storytelling, facial expressions, and body posture (Borup et al., 2011; Mehrabian, 1971).

Community of Inquiry. The framework that describes the relationship between cognitive presence, social presence, and teaching presence, as the key components to creating an educational experience within a community (Garrison et al., 2000).

Social Presence. Establishing oneself as a "real person" to others in the online community through open communication, emotional expression, and group cohesion (Garrison et al., 2000). This involves the noticeable presence of the person and the interpersonal relationships within a communication (Short et al., 1976).

Teaching Presence. Includes the elements of instructional design and organization, facilitation of discourse, and direct instruction that occurs in an online classroom and provides structure to the interactions between peers, instructors, and content. To be affective, teaching presence must include content dissemination, assessment, feedback, and discussion facilitation (Swan et al., 2008). 
Instructor Social Presence. The overlap between teaching presence and social presence describes the interaction of the instructor within the online course. It is the representation of the instructor as a "live" person involved in the educational process (Richardson et al., 2015) and instructor attributes that go beyond the design and implementation of coursework (Sheridan \& Kelly, 2010).

Student Engagement. The affective, cognitive, and behavioral outputs a student demonstrates when taking part in learning activities, which are based on structural and psychosocial factors, and which lead to academic and social consequences (Kahu, 2013).

\section{Summary}

This chapter introduced student engagement as a critical issue in online education. It described how instructor social presence and asynchronous technology may be part of the solution to student engagement issues. Engagement impacts student outcomes, including retention in online learning programs (Ali \& Smith, 2015; Byrd, 2016). The increased use of online learning as an educational model requires instructors and institutions to examine their practices to ensure student success through improving student engagement. Factors associated with improved student engagement were discussed. The role the instructor plays in increasing a student's willingness to participate in online learning was illustrated. Descriptions were provided about how instructor social presence might play a particularly important role in the development of the instructor-student relationship and provide a sense of community, both important contributors to student engagement. The impact of communication technology on the development of instructor social presence in an online course was explored. This study postulated that the use of asynchronous video in an online occupational therapy course would 
positively impact students' perceptions of instructor social presence and student engagement, more than text-based communication.

This chapter also illustrated a lack of quantitative data to support previous researcher's assumptions that a connection between instructor social presence and student engagement exists. Theoretical frameworks provided the basis for examining instructor social presence and student engagement as separate but intertwined concepts that may both be influenced by communication methods. The use of asynchronous video as an important and evolving educational tool was described, and the limitations of the current literature to support all three constructs - student engagement, instructor social presence, and asynchronous video - was presented.

The use of asynchronous video and text-based communication to foster instructor social presence and student engagement, as measured by a Likert scale survey and discussion post data count was researched in the current study. Further evidence of the importance of student engagement, instructor social presence, and asynchronous video as used for online higher education learning is described and the methods, data analysis, results, and conclusions of this study are explained. Contributions of this research to the teaching and learning practices of online educators and institutions is addressed. It is believed that this study may help online or blended format instructors utilize the most appropriate communication medium to increase student engagement and improve the instructor-student relationship through increased instructor social presence. 


\section{Chapter 2: Review of the Literature}

Instruction in online education has moved beyond simple written text to establish communication between class participants (Revere \& Kovach, 2011). Technological developments have created more opportunities for interaction, which allows for a better conveyance of immediacy behaviors and the establishment of relationships between students and teachers (Borup et al., 2011; Griffiths \& Graham, 2009; Tomas et al., 2015). Enhanced communication may increase students' engagement in online learning by developing a deeper sense of community and limiting feelings of isolation, which also improves student retention (King, 2014; McMahon, 2013; Tinto, 1997).

Essential to the future of online learning is the ability of faculty and institutions to overcome retention issues, which continue to limit the success of students in the online environment (Allen \& Seaman, 2014; Xu \& Jaggars, 2014). Estes (2016) claimed that increasing student engagement directly contributed to a decline in student attrition rates, and faculty presence was a critical component to student engagement. Faculty presence included developing and sustaining an organized course infrastructure with clear expectations and communication, establishing a sense of classroom and institutional community, and facilitating self-directed learning (Estes, 2016). The concepts of faculty presence described by Estes (2016) closely resemble the concept of instructor social presence, which was defined by Richardson et al. (2015) as the overlap between the COI principles of teaching presence and social presence. This overlap constitutes the "live" parts of the course where the instructor facilitates discourse and delivers content, while also demonstrating that they are a real person through open communication and affective expression (Richardson et al., 2015). Investigating the factors involved in using technology to enhance instructor social presence and improve student engagement in online classes is essential for combating student issues, such as retention. 
Asynchronous video may be one way to use technology for improving student engagement by increasing students' perceptions of instructor social presence. Online learning is criticized for its lack of humanization, or the inability of faculty and peers to perceive each other as real, without the audio and kinesthetic clues afforded by face-to-face interaction (Weiss, 2000). Humanization is similar to the construct of social presence, which is the ability of participants in the learning environment to present themselves as real individuals during communication (Garrison et al., 2000; Weiss, 2000). The ability of asynchronous video to convey the verbal and non-verbal immediacy cues necessary to create closeness and increase social presence is indicated in the literature (Borup et al., 2011, 2012, 2014). The online education environment requires students to have increased self-direction and independent learning skills, which can be challenging for students who are not prepared (Xu \& Jaggars, 2014). The use of asynchronous video to create a connection between students and instructors through instructor social presence may increase student engagement.

In most online learning literature the role of the instructor in the online class has been minimized secondary to the establishment of social interactions between peers (Lowenthal, 2016). More recently, the focus of education research has shifted back to the importance of online instructors, and their role in facilitating the learning process, engaging students, and increasing student satisfaction (Estes, 2016; Ma et al., 2015). Phirangee et al. (2016) suggested that the instructor-student relationship may be paramount to the development of a sense of community in online learning, and the biggest influence on student participation. Instructor social presence may be even more important than peer-to-peer social presence for influencing student participation and overall student success (Phirangee et al., 2016). Chickering and Gamson (1987) described the principles of good practice in higher education teaching, which 
included the importance of instructor-student interaction. These principles, though originally developed for face-to-face teaching, have been widely implemented in online education (Oncu \& Cakir, 2011). Developing instructor-student communication is essential to student motivation and involvement in the learning process (Chickering \& Gamson, 1987).

Imperative to the development of the student-teacher relationship is the instructor's use of social presence to create an atmosphere of open communication, group cohesion, and effective expression, as defined by the COI framework (Garrison, Anderson, \& Archer, 2010; Pollard et al., 2014). Through instructor social presence, humanization of the instructor allows students to develop a deeper connection to the learning community and feel motivated by their interactions with a real individual (Estepp \& Roberts, 2015; Glazier, 2016; Griffiths \& Graham, 2009; Weiss, 2000). The ability of asynchronous video to convey verbal and non-verbal immediacy behaviors creates a greater sense of community, and may allow for a better expression of instructor social presence (Estepp \& Roberts, 2015; Griffiths \& Graham, 2009). Instructor social presence is often cited as the potential mediating factor between the use of asynchronous video and student engagement, but a direct investigation into this connection does not exist (Glazier, 2016; Mcdowell, 2011; Tomas et al., 2015; Zak, 2015). Additionally, the development of instructor social presence by asynchronous video has been qualitatively established in the literature, but it has not been supported by quantitative data (Borup et al., 2014). A quantitative study regarding the ability of asynchronous video to enhance instructor social presence and student engagement in an online class is necessary for the development of online teaching andragogy.

Understanding the influence of asynchronous video on students' perceptions of instructor social presence may help online and blended format instructors facilitate the necessary studentteacher relationships to build a sense of classroom community, and encourage student 
engagement (Borup et al., 2014; Glazier, 2016). Examining the historical foundations of online learning and adult learning theory demonstrates the evolution of online instruction and the usefulness of technology to improve andragogy and student outcomes. Through the lens of the previously established COI framework and Kahu's Student Engagement framework, an underlying connection between the communication medium, instructor social presence, and student engagement can be viewed. Research suggested a significant relationship between the role of the instructor and student engagement in an online classroom, along with the important long-term consequences of student retention based on student engagement levels (Bowers \& Kumar, 2015). While the role of the instructor has been verified, the way in which that role is established is less clear (Lowenthal, 2016; Pollard et al., 2014). Indications from the literature suggested that instructor social presence may be a significant factor in student engagement (Borup et al., 2014). Understanding the relationship between instructor social presence and student engagement, and the utilization of asynchronous video for developing both in an online course, may be critical to the future of online learning and should be further explored.

\section{Historical Foundations of Online Learning}

Distance education began with correspondence courses that required little to no interaction with others but relied on the postal service and text-based exchanges to reach a new population of learners previously inaccessible (Caruth \& Caruth, 2013). According to Caruth and Caruth (2013), over time and through many developments in technology, distance education has advanced into online learning, which touts the ability to educate learners in a way comparable to face-to-face learning. The idea of distance education arose from the need to reach a new population of learners who did not have access to face-to-face courses (Caruth \& Caruth, 2013). Correspondence courses were the solution to a social justice issue, providing education to adults 
who would not have had the ability to attend school otherwise (Archer \& Garrison, 2010). The idea of inclusivism and reaching learners in a flexible manner, which eliminates the barriers of time and space, continues to dominate the dialogue surrounding online learning. Today the new generation of online learners are not only the students unable to access face-to-face classes but are in essence, all learners at any level of schooling (Archer \& Garrison, 2010). Online learning is being embraced in primary, secondary, and post-secondary education, with a significant body of research growing to support its use in all practice areas (Caruth \& Caruth, 2013).

Over time, generations of distance education courses have been distinguished by the types of technology utilized to connect students, instructors, and content. Archer and Garrison (2010) are among several researchers who have attempted to classify the generations of online learning. Their model will be the focus of the current discussion due to its emphasis on the methods of communication for distinguishing generations of distance education. First generation distance education included correspondence courses that used a single print medium for communication. Considered slow asynchronous distance education, this generation of courses addressed the barriers of time and space, but lacked responsiveness, and impersonal communication led to high dropout rates. Almost immediately, improving communication became the focus of distance educators, who attempted to reduce retention issues by utilizing telephone and occasional face-to-face meetings to improve student satisfaction. This early attempt at synchronous and blended learning was the first revolution in distance education and a significant transition to focusing on creating a connection between learners and instructors (Archer \& Garrison, 2010).

Generation Two, also called synchronous distance education, closely resembled traditional classroom instruction and improved communication by allowing for two-way 
discussions between instructors and students (Archer \& Garrison, 2010). Unfortunately, the improved communication afforded by audio, and occasionally video conferencing, removed the benefit of learning at different times. Generation Two resulted in an increased ability for distance learners to participate in learning communities and construct knowledge through social interaction, which led to higher student satisfaction and retention. However, the lack of flexibility in the delivery of this mode of learning in that Generation Two distance education became more of an add-on tool for traditional classes, and not a separate mode of educating (Archer \& Garrison, 2010).

Generation Three distance education is considered asynchronous distance education, and comprises what most people term e-learning or online education (Archer \& Garrison, 2010). The rise of the internet and the use of computers to transmit knowledge and communication across time and space has allowed for the benefits afforded by the first generation of distance education, combined with the connectedness and presence enabled by the second generation (Archer \& Garrison, 2010). While critics continue to question the efficacy of online education as a comparable or even superior way of educating learners, research trends indicate that online learning is both adequate for educating students, and rising in popularity (Allen \& Seaman, 2014; Caruth \& Caruth, 2013).

In higher education, online learning is a desirable method for institutions to adopt due to the changing demographics of learners entering higher education institutions and the need to reduce the cost of education (Caruth \& Caruth, 2013). Growth in technology continues to improve the methods and means for delivering online education in an interactive and constructive way. Throughout the development of online learning, theories have emerged to address the changing landscape of education and to inform instructor practices. Particularly of 
interest for this study is adult learning theory because the population being studied is higher education students in a post-secondary university.

\section{Adult Learning Theory}

Theories of adult learning have progressed over the last several decades. Their primary goal has been trying to explain the ways in which adult learners obtain knowledge, the roles of the learning community, and the motivations behind adult learning. While no one theory dominates the literature on adult learning, discourse over the appropriateness and applicability of various models creates an understanding of the complexity of the adult education field. Transformative Learning Theory, Andragogy, and Self-Directed Learning Theory, are primary concepts mentioned in the discussions of adult learning theory in current literature (Archer \& Garrison, 2010; Merriam, 2001).

Transformative Learning Theory assumes that adult learners already have experiences and beliefs that shape their way of viewing the world, and acquiring new knowledge requires students to transform their internal frames of reference (Mezirow, 1997). Essential to this learning theory is the ability of adults to be autonomous and responsible for their own thinking (Mezirow, 1997). In Transformative Learning Theory, the goal of educators is to help adult learners develop the critical thinking and inquiry skills necessary to cultivate knowledge through discourse, problem-solving, group collaboration, and independent inquiry (Mezirow, 1997). Through self-direction, adult learners can refine their previous frames of reference to accommodate new knowledge and develop autonomy (Mezirow, 1997). This theory is similar to the concept of andragogy, which is also relevant to adult learning theory.

The term andragogy was developed to describe the field of educating adult learners. According to Blackely and Sheffield (2015), andragogy assumes that the adult learner is 
independent and self-directed, has life experiences to draw from, seeks knowledge that can be immediately applied, is ready to learn, and is intrinsically motivated to learn. Developed by Malcolm Knowles, andragogy has been criticized as not necessarily describing an adult learner but is better used to describe a more mature or developed learner, which does not equate to the age of the learner (Archer \& Garrison, 2010).

The principles of andragogy have been explained as more learner-focused, as opposed to pedagogy, which is more teacher-focused (Blackley \& Sheffield, 2015). This distinct and important difference offers a model for viewing the adult learner and provides guidance for creating courses that place the learner at the center of the process. Through the lens of andragogy, learners must work in a cooperative, collaborative environment where they are interested in the information and can see a direct impact on their abilities and knowledge (Knowles, 1984). What is necessary for adult learning is for students to understand why they are learning. It is essential to move learners beyond mere memorization to solving problems, applying knowledge, and actualizing the information in real scenarios (Knowles, 1984). Strongly linked with both constructivist and experiential learning theory, andragogy provides one model for viewing adult learning, which emphasizes the independence of the learner.

Self-directed learning is an important construct within adult and online learning theory. This type of learning emphasizes the central role the adult learner plays in the educational process (Garrison, 1997; Merriam, 2001). The self-directed learning model developed by Garrison (1997) explores the relationships between self-management, self-monitoring, and motivation, as interrelated constructs that work together to help adult learners form knowledge. Self-directed learning implies that a person can lead their own learning. This includes not only the cognitive ability to learn but also the motivation and self-management processes needed for 
obtaining learning outcomes (Garrison, 1997). Relevant to aspects of the current research is the effect of this relationship between the adult learner and the instructor on creating an environment conducive to self-directed learning.

\section{Classroom Community}

Creating an environment suited for the development of self-directed learning, which also motivates students, requires building a classroom community. Rovai (2002) explored the ability of instructors to create a classroom community in an online setting. Based on the four dimensions of spirit, trust, interaction, and common expectations related to goals and learning, a classroom community allows learners to feel supported and capable. Spirit included the learner's feelings of cohesion and membership in a group. This helps reduce feelings of isolation, which can lead to retention issues. Trust illustrated the learner's ability to rely on others to provide accurate and credible information, as well as supportive discourse. Interaction is both the means and the ends of a classroom community. Students must interact to develop a sense of community, but building a sense of community allows for interaction. Common expectations important to building a sense of community included the learner's commitment to quality and the educational purpose of the community (Rovai, 2002). Related to self-directed learning, and adult learning theories, the classroom community allows for the development of autonomy, self-regulation, and intrinsic motivation necessary for pursuing educational goals. Once thought to be impossible in an online environment, classroom community has been established as a motivating factor that positively influences online learner outcomes (Byrd, 2016).

Byrd (2016) described the classroom community as a system that may enhance the online student's experience and leads to improved student engagement. A key aspect of classroom community is the students' willingness to engage in the learning process (Byrd, 2016; Rovai, 
2002; Tinto, 1997). Essential to the development of classroom community is the interaction between learners and instructors (Byrd, 2016). Beyond just the instructor-student relationship, the development of a community in general has been shown to be a positive predicting influence on student engagement. Byrd (2016) established that a sense of community is essential for the student experience and student success, as well as a direct contributor to student engagement. The researcher suggested that social presence and interaction are essential for the development of a classroom community and student engagement. A sense of classroom community may predict students' persistence in online learning by encouraging engagement and social interaction, which leads to reduced feelings of isolation and loneliness (Tinto, 1997).

In a similar manner, Rovai (2002) explained that developing a sense of classroom community can positively influence a student's persistence by increasing the amount of information exchange that occurs between learners, and improving student commitment and satisfaction with the online learning experience. Developing a classroom community in the online learning environment can impact the student's ability to be successful, autonomous, and participatory. A sense of classroom community can improve discourse and collaborative learning, which leads to transformations in thinking and self-directed practices for future learning (Rovai, 2002).

Important to this study was the use of classroom community as a method for motivating students to engage in learning beyond what is required to earn a particular grade in the course. In this study, the development of classroom community was purposefully used to develop selfdirected learners who were intrinsically motivated to participate in academic activities. A sense of community provides the necessary affective support for students, through interactions with peers and instructors (Rovai, 2002). These personal interactions lessen the inherent transactional 
distance in an online course which allows students to feel supported, and subsequently increases student engagement in the overall learning experience (Byrd, 2016; Rovai, 2002; Tinto, 1997). By increasing instructor social presence, the assumption was made that a stronger sense of classroom community would be developed and in turn students would be more inclined to engage in voluntary discussions. The self-directed nature of online learning makes it critical to develop learners who are self-regulated so student outcomes and persistence may also improve (Glazier, 2016). One particular method for developing a sense of classroom community may be the use of video to engage students (Moore, 2014).

\section{Asynchronous Video}

As communication technology has developed, a significant amount of research has investigated the efficacy of text, audio, and video communication to enhance student outcomes in online learning. In the early days of online learning, text-based communication used in online teaching was criticized for its inability to convey the verbal, and nonverbal immediacy behaviors thought to be essential for critical discourse (Weiss, 2000). Garrison, Archer, and Anderson (2000) found that text-based communication was sufficient for conveying some immediacy behaviors and allowing the development of social presence among learners. Other researchers felt a lack of humanization in online learning was a direct contributor to students' feelings of isolation and high attrition rates (Ali \& Smith, 2015; McMahon, 2013; Weiss, 2000). As asynchronous video became available to all educators, researchers began working to determine if this new communication medium was the solution to student outcome issues (Borup et al., 2011, 2012, 2014). Subsequent studies have confirmed that asynchronous video can be a valuable educational tool for online learning, though understanding the mechanism for its positive effect has received little attention (Borup et al., 2011, 2012, 2014). 
A significant body of literature has established asynchronous video as an important medium for creating a relationship between instructors and students (Borup et al., 2011, 2012, 2014; Glazier, 2016). A series of articles researching the use of asynchronous video in online courses provided qualitative and mixed methods data to suggest that asynchronous video is effective in conveying immediacy behaviors, social presence, and establishing an emotional connection between all members of the classroom community, including teachers and peers (Borup et al., 2011, 2012). Other researchers have found that asynchronous video is superior to text-based communication for motivating students, by making the instructor feel more present and developing a sense of community (Borup et al., 2014; Glazier, 2016; Griffiths \& Graham, 2009; Moore, 2014).

Humanization is one way that asynchronous video has been able to change the face of online learning to develop stronger connections between instructors and students (Glazier, 2016). According to Weiss (2000) online learning devoid of audio and visual cues does not allow students to feel like they are communicating with real people, but that they are learning in a sterile, lonely environment, which leads to retention and engagement issues. The introduction of asynchronous video to online learning may allow for increased humanization of instructors in the online classroom. Glazier (2016) found that video announcements humanized the instructor of an online class by building their rapport with students, which in turn affected student retention. By facilitating open communication and allowing for affective expression, asynchronous video is able to convey social presence while also allowing the instructor to deliver content. These findings support the use of asynchronous video for conveying instructor social presence which impacts student engagement (Glazier, 2016). 
Unique to this study is the examination of the usefulness of asynchronous video to increase student's perceptions of instructor social presence in a fully online course. Borup et al. (2014) explored the use of asynchronous video versus text-based communication for conveying instructor social presence in a blended course, using a mixed-methods approach. These researchers studied the use of asynchronous video for providing assignment feedback. Quantitative analysis of the data did not indicate any significant difference in the students' perceptions of instructor social presence between the two groups. Through qualitative analysis, the researchers did find significant indications that instructor social presence was impacted by video technology. Student interviews revealed that participants felt video made it easier to feel connected, was more personal, allowed for more interaction, and expressed more emotions than text-based feedback. Borup et al. (2014) attributed these contradictory findings to the blended environment in which the study was conducted. Notably, the researchers emphasized that the face-to-face component of the blended environment may have allowed students to perceive instructor social presence despite the medium of feedback, and suggested a similar study be conducted in an entirely online environment (Borup et al., 2014).

Kushnir and Berry (2014) investigated the use of educational technology on student satisfaction in online courses and found that asynchronous video led students to feel more connected than text-based communication. This led to improved student satisfaction. The study participants reported these feelings were due to increased instructor social presence. In fact, the higher the perceived instructor social presence, the higher the student satisfaction, and the more connected the students felt to the instructor (Kushnir \& Berry, 2014). Video messaging may allow instructors to demonstrate necessary immediacy behaviors to convey themselves as real people to the students, and create a deeper sense of community in the online classroom. 
The literature also suggests a connection between the use of asynchronous video and increased student engagement (Chen, Lambert, \& Guidry, 2010; Draus et al., 2014; Ma et al., 2015; Mcdowell, 2011; Tomas et al., 2015). Draus et al. (2014) found that as little as one hour of instructor-generated video content increased student participation in discussion forums by more than $14 \%$. The authors attributed this increase in student engagement to the increased instructor teaching and social presence created by the videos. This particular study did not account for the additional increase in instructor engagement that also occurred in the discussion forums of the group who received instructor videos, making it challenging to attribute the results directly to the use of video (Draus et al., 2014).

Borup et al. (2011) studied the use of asynchronous video in blended classrooms as a method for communication utilized by both instructors and students. Student qualitative responses to the use of video indicated that there was a higher conveyance of instructor immediacy behaviors and social presence than in online portions of the course that did not use video. Asynchronous video allowed for flexibility in learning while still developing a connection to the instructor which improved student satisfaction with the course. While some students did not see the benefits of asynchronous video over text-based communication, the positive feedback on the use of video in blended courses was evident based on qualitative analysis (Borup et al., 2011).

Zak (2015) alternatively found that asynchronous video positively impacted development of a sense of community among students but did not specifically enhance student engagement. Again, through qualitative means, the researcher was able to establish that students felt asynchronous video improved the humanization of the course and improved their understanding of the course material. These findings were not supported through the quantitative means used in 
this study. The outcome of this research furthers the idea that asynchronous video may not be directly linked to student engagement but is mediated by the building of community, and perhaps the role of instructor social presence (Zak, 2015).

Repeatedly researchers utilizing asynchronous video have attributed an increase in student engagement to the development of the instructor-student relationship and establishment of a learning community, which is created by the audio and visual presence of the instructor (Chen et al., 2010; Mcdowell, 2011; Tomas et al., 2015). However, this notion, based on the qualitative comments of participants and justified through immediacy behavior theory, has not been directly investigated (Borup et al., 2011; Chen et al., 2010; Mcdowell, 2011; Tomas et al., 2015). Additional study on the efficacy of asynchronous video to improve both instructor social presence and student engagement is needed to determine whether asynchronous video is a preferable method of instructor-student communication in online learning.

\section{Student Engagement}

Student engagement is an important predictor of student outcomes, such as retention, in online learning and has gained recent attention in education literature because of the challenge educators face when trying to impact student engagement in an online environment (Ali \& Smith, 2015; Estes, 2016; McMahon, 2013). Previous studies have shown that student retention issues decline as engagement increases in online courses and that early engagement is a key factor in predicting student persistence (Angelino et al., 2007). Potentially thought of as energy in action, engagement represents the affective, behavioral, and cognitive energy that one expends in a school or classroom, which influences learning outcomes (Lawson \& Lawson, 2013).

Lawson and Lawson (2013) described affective engagement as the student's emotional, psychological and social attachments that occur in the learning environment and can be related to 
student interest, enjoyment, boredom or anxiety during learning activities. In a broader sense, affective engagement refers to the student's feelings of belonging and their relationship to their peers, instructors and the larger institutions. Positive affective engagement leads to increased motivation to persist in academic challenges. Cognitive engagement includes the student's investment in the learning activity and their disposition towards school. This includes the amount of energy they exert towards school work and their willingness to persist despite difficulties in learning. High cognitive engagement indicates higher self-regulation and metacognition, which leads to improved student outcomes and retention. Behavioral engagement is the most visible form of student engagement and includes the amount of time a student spends on a task, their participation in learning activities, and their willingness to follow the rules and social norms of the classroom (Lawson \& Lawson, 2013). All three categories of engagement are important to the development of the online learner and their ability to be successful in the classroom.

Pittaway (2012) further elaborated on the concept of student engagement by emphasizing the role of the instructor in the teaching and learning process. The Engagement Framework she described emphasized that the relationships developed within the learning environment are essential to engagement. Based on the concept that students and instructors must simultaneously be active participants in the learning process, student engagement can be described as a reciprocal process between the student and the learning context. Active, self-directed and collaborative learning are emphasized in this framework of student engagement, which reinforces the importance of the role of the instructor (Pittaway, 2012). The online teacher may have the most substantial influence on student engagement over all other factors, such as intrinsic motivation and external rewards (Zepke et al., 2010). Building rapport between teachers 
and students can influence a student's level of engagement, and has been shown to effectively improve retention in online classes (Bowers \& Kumar, 2015; Glazier, 2016; Heyman, 2010). Engagement requires faculty to be simultaneously engaged in the learning process. Members of the learning community must also develop constructive interpersonal relationships, and students need to take responsibility for their personal learning (Pittaway, 2012). Within these requirements is the essential aspect of developing the instructor-student relationship in order to improve student engagement (Estepp \& Roberts, 2015). Communication between the student and instructor leads to increased student engagement and higher student motivation (Estepp \& Roberts, 2015). The influence of the instructor on student engagement is an important construct as research continues to establish engagement as a strong predictor of positive student outcomes including retention.

Kahu's (2013) student engagement framework provided a backdrop for understanding the complex nature of engagement and how multiple variables influence the development of student engagement in an educational setting. The framework also explored the influence of student engagement on student outcomes, including retention. Based on existing literature, the framework provided perspective on how technology and instructor social presence may impact the development of student engagement, which is important for the current study.

Kahu's (2013) framework explored student engagement as a multifaceted construct with affective, behavioral, and cognitive components. Affective components include student enthusiasm, interest and belonging (Kahu, 2013). These concepts are important for the development of a learning community and are further supported by Rovai's (2002) findings, which indicated that affective support may address student persistence issues and is linked to student engagement (Ali \& Smith, 2015; McMahon, 2013). Cognitive components of 
engagement include deep learning and self-regulation factors, both of which are necessary for student learning and success in the classroom (Kahu, 2013). The behavioral aspects of time and effort, interaction, and participation are most typically associated with student engagement (Kahu, 2013). These outward signs of engagement are the easiest to measure in an objective manner and are therefore a common way of collecting data about online student engagement (Draus et al., 2014). Kahu's (2013) framework suggested that the structural and psychosocial influences of the institution and students impacted the development of student engagement. Specifically, the psychosocial influence of the teacher-student relationship is important for the current study.

The instructor-student relationship. The instructor-student relationship has been shown to be a major influence on the development of student engagement. It has been suggested that instructors should focus on designing activities that specifically enhance the instructor-student relationship if their goal is to improve student engagement (Ma et al., 2015). Other research investigating how to improve student engagement indicated that the development of studentteacher rapport, instructor feedback, and the instructor's ability to convey information about the class were all important to online students (Estepp \& Roberts, 2015; King, 2014). The thread in these key elements is the essential role the instructor plays in the development of student engagement.

In a study aimed at describing the experience of engagement in the online classroom O'Shea et al. (2015) used qualitative student feedback to illustrate the important role of the instructor in the development of a student's sense of community and engagement in online learning. In this study, several students pointed to the importance of the presence of the instructor in the course as a vital component to their learning. One student specifically mentioned 
that the instructors increased engagement in the online discussions, and facilitated their engagement in the course (O'Shea et al., 2015). This description of the instructor's social presence enhancing the student's willingness to engage is an important observation to further evaluate through quantitative research.

Student volition. In addition to the importance of the instructor, the importance of student volition in academic engagement must be evaluated (Poll, Widen, \& Weller, 2014). Unique to this study is the use of voluntary discussion boards as a measurement of student engagement. The use of voluntary discussion boards allows students to express their affective, cognitive, and behavioral engagement in the learning community. Affective engagement is demonstrated by their interest in discussing course-related information above and beyond what is required of the class. Cognitive engagement is demonstrated by the self-regulated and selfdirected learning occurring by thinking about, discussing, and developing meaning from nonrequired discussions. Behavioral engagement is demonstrated through participation and time and effort that is not required for external reward but may result in an intrinsic reward. Voluntary discussions allow for expression of all three forms of engagement and are a unique feature of the current research. According to Poll et al. (2014) one of the most important principles of online student engagement, especially when working with adult learners, is to be flexible and individualized in learning options. Student-centered learning may be achieved by demonstrating flexibility and sensitivity to the unique needs of the learner (Poll et al., 2014). While compulsory participation has its place in creating discourse and holding students accountable, voluntary participation may be a better representation of true self-directed learning and student engagement (Gulati, 2008). 
Kahu's (2013) framework, along with the approaches of other theorists, provided an understanding of the important and complex role of student engagement in the learning experience. With the significant impact on student outcomes, specifically retention, student engagement is an important factor to account for when designing an online learning curriculums. Understanding the contributing roles of the instructor, students, and institution to the development of student engagement is central to developing online teaching practices. More recently the role of the instructor has been the focus of research.

\section{Role of the Instructor}

Faculty participation is a key factor in the development of student engagement, with faculty visibility and the development of personal connections between students and faculty as key components for creating a classroom community conducive to student engagement (Estes, 2016). Student satisfaction with an online course often includes considerations of faculty availability and interactivity, making it essential for faculty to establish a presence in online courses (Estes, 2016). It may be more challenging in an online course for instructors to project their availability to students. This requires instructors to develop strategies to enhance their visibility and their ability to provide support remotely to students (Bowers \& Kumar, 2015). Bowers and Kumar (2015) found that in comparison to face-to-face classes, online instructors were better able to project their presence and create a sense of connectedness between learners and instructors, ultimately leading to greater student engagement and success. The instructor's ability to communicate clear expectations, help students stay on track, and provide feedback were found to be the most influential behaviors in enhancing students' sense of connectedness (Bowers \& Kumar, 2015). 
The role of the instructor is not only to provide basic information but to mentor and support the online learner for the development of classroom community, a sense of connectedness, and student outcomes (Bowers \& Kumar, 2015; Estes, 2016; Sheridan \& Kelly, 2010). The specific role of the instructor related to their teaching and social presence, and the impact on the development of student engagement, requires additional investigation.

\section{Community of Inquiry (COI)}

The COI framework, developed by Garrison, Anderson, and Archer (2000) represented the interplay of cognitive, teaching, and social presence as the driving forces for creating educational experience for students in an online environment. While it has undergone revisions over the years, the core principles of this popular model for examining online learning experiences has largely remained the same. Cognitive presence is described as the ability of the learner to create meaning from information and is essential to the development of critical thinking skills. Teaching presence includes the design and facilitation of learning experiences and plays a supportive role in cognitive and social presence. Included in teaching presence is course design, content delivery, and discussion facilitation that occurs during a class which drives the educational process forward. Social presence is defined as the ability to project oneself as a real person and is demonstrated through affective expression, open communication, and group cohesion (Garrison et al., 2000). Noteworthy for this study is the concept that Swan et al. (2008) described as the instructor presence which had previously been investigated as teaching presence, but may also include the teacher's social presence demonstrated in an online course. Social presence and teaching presence have both been explored as primary factors in the development of student engagement and retention in online learning. Bowers and Kumar (2015) concluded that high drop-out rates in online learning are a direct result of a lack of teaching and 
social presence. Specifically, they determined that students felt connected when there was a high degree of teaching and social presence, which led to better student success and higher student engagement. The authors boldly stated that teaching and social presence are critical for engagement and retention in online learning (Bowers \& Kumar, 2015). It may also be possible to convey group cohesion and open communication in online classes at a higher rate than in faceto-face classes by utilizing instructor announcements (Bowers \& Kumar, 2015). The only area that was not easily conveyed in the online environment was affective expression. The researchers suggested that the face-to-face benefits of a traditional class allowed for a better expression of humor, emotions, and self-disclosure. They also suggested that those same representations of affective expression may be conveyed through video in online courses (Bowers \& Kumar, 2015). This assertion was not specifically investigated, though, and requires further investigation to determine if asynchronous video can increase teaching and social presence in an online course, possibly through an increase in affective expression while delivering content and facilitating discourse.

Teaching presence. Teaching presence is an essential component of the COI framework, and mediates social presence and cognitive presence to create a space for knowledge exchange, peer learning, and incorporation of information to form meaning (Garrison et al., 2007). Teaching presence has been established within the COI framework as the part that accounts for the instructional design and organization, facilitation of discourse, and direct instruction necessary for participating in the educational experience (Anderson, Rourke, Garrison, \& Archer, 2001). According to Anderson et al. (2001), included in the instructional design and organization concept is the need for instructors to set curriculum, design teaching methods, establish timeframes, utilize the communication medium, and establish etiquette in the online 
forum. Under the section of facilitating discourse is the need to identify areas of conflict, seek consensus, encourage others and reinforce contributions, set the climate for learning, promote discussion, and assess how the process is working within an online course. Included within the concept of direct instruction is the need to present questions, deliver content, focus discussions, summarize and provide feedback, interject new information, and respond to concerns. Together these critical elements, required for successful online learning, constitute the construct of teaching presence within the COI framework (Anderson et al., 2001).

Within the current study the instructor announcements in both groups were designed to convey teaching presence. The elements of utilizing the communication medium, encouraging contributions, setting the climate for learning, promoting discussion, and all components of delivering content, were addressed in each announcement. While not the sole responsibility of the teacher in an online classroom, teaching presence has been primarily viewed from the lens of the instructor (Bowers \& Kumar, 2015).

In an online classroom. teaching presence may enhance student's perceptions of learning, and foster student engagement through the development of community (Sheridan \& Kelly, 2010). Sheridan and Kelly (2010), established that students rated the instructor's ability to create an atmosphere conducive to sharing feelings, and providing a place of belonging, as essential to student success. The researchers also mentioned that a piece of teaching presence seemed to be lacking from the traditional definition within a COI framework. Instructor attributes were conveyed during the course, which contributed to the atmosphere of closeness the students perceived (Sheridan \& Kelly, 2010). This concept is termed instructor social presence in more current literature. Ladyshewsky (2013) further described the importance of instructor teaching presence as the way in which instructors formed the online learning environment so students 
could be engaged. By facilitating discourse, instructors were able to structure discussions so that students felt more engaged and satisfied with the online experience. Essential to the value of this discourse for promoting student learning is the need for high social presence, as well as, high teaching presence in an online classroom (Ladyshewsky, 2013). Teaching presence is important in online learning, but the traditional concept of teaching presence from the COI framework may be insufficient for describing the unique way in which an instructor facilitates student engagement in the classroom.

Social presence. Social presence has its roots in the concept of immediacy behaviors and has been extensively researched in the literature surrounding online education (Rourke et al., 2007). As online communication developed, so did the ability of online instructors to convey the affective interpersonal connections that were typically seen in face-to-face classrooms only (Rourke et al., 2007). The components of social presence included open communication, which is demonstrated through risk-free expression, group cohesion demonstrated through collaboration, and affective expression possibly demonstrated through things such as emoticons (Garrison et al., 2010). Social presence may play a supportive role in the development of cognitive presence, or may directly influence the affective outcomes expected from education (Garrison et al., 2000; Rourke, Anderson, Garrison, \& Archer, 2007). The development of community and collaboration within the online learning environment may be the direct result of social presence (Swan et al., 2009).

Over years of investigation, several researchers have suggested alternate models of the COI framework. One attempt at re-creating the model by Armellini and De Stefani (2015) placed social presence at the core of the educational experience, making it a much more prominent feature in the development of a community. Based on their action research, Armellini and De 
Stefani (2015) concluded that social presence was not necessarily a stand-alone construct in the development of community but was an essential component of teaching and cognitive presence. The findings of these researchers also indicated the key role the instructor played in the development of community, particularly when the function of teaching became social (Armellini \& De Stefani). The researchers termed this overlap of teaching presence and social presence as interactions for learning (Armellini \& De Stefani). The emphasis on the role of instructorstudent interactions to create higher-order thinking was deemed essential for the development of student engagement (Armellini \& De Stefani). While the traditional COI framework continues to be the standard model for understanding the development of community through cognitive, teaching, and social presence, alternative views of the framework point to an increased emphasis on social presence as an essential factor in online learning (Armellini \& De Stefani; Whiteside, 2015).

Investigations into the construct of social presence, independent from teaching and cognitive presence, has resulted in new models to explain this unique and important element of online learning. Whiteside (2015) suggested a new Social Presence Model that depicted social presence as a much more complex construct than originally described by the COI framework. This researcher's work, based on a multiyear, qualitative study of multiple courses, concluded that social presence could be defined by the original sub-categories of affective expression, open communication, and group cohesion described by Garrison, Anderson, and Archer (2000). Additionally, "participant knowledge and experience, and instructor involvement" were included (Whiteside, 2015, p. 11). Again, this author emphasized the unique contribution of the instructor to the development of community through social presence. Though this research was conducted 
in a blended format, similar if not more instructor interaction may be needed in fully online courses (Whiteside, 2015).

Social presence has long been established as a critical component to the development of a community in online learning (Rourke et al., 2007; Swan \& Shih, 2005). Short, Williams, \& Christie (1976) originally described social presence as a continuum of awareness of the interpersonal nature of communication when interacting with others, or the perceived realness of an individual during an interaction. Face-to-face communication was placed high on the continuum, indicating that immediacy and intimacy were easily perceived by communication parties, while text-based communication was placed on the low end of the continuum (Short et al., 1976). As technology has developed to allow for higher levels of fidelity in online communication, the concept of social presence in online learning has garnered more attention (Borup et al., 2011). Developed from collaborative constructivist theory, the COI framework provides the building blocks for understanding this essential, yet complex construct (Rourke et al., 2007; Swan et al., 2009). Current research continues to explore the importance of social presence for the learning experience, especially given the new affordances of technology and online learning capabilities (Borup et al., 2014; Glazier, 2016; Lowenthal, 2016). Throughout the research on social presence, the role of the instructor continues to present itself as an important variable to consider when designing and implementing an online course. Instructor social presence has been indicated as necessary for student learning in the current literature but requires further investigation to determine its overall impact on online teaching and learning.

\section{Instructor Social Presence}

Instructor social presence has been suggested as a separate component of the COI framework due to its potential ability to advance the development of community and student 
outcomes in online learning (Lowenthal, 2016; Pollard et al., 2014; K. Swan \& Shih, 2005). While the original COI framework implied that social presence was both the responsibility of the learner and the teacher, the role of peer social presence gained the most attention by early researchers (Lowenthal, 2016). As instructors realized that they played a significant role in student outcomes and that their involvement was essential for student success, the concept of instructor social presence gained more attention (Borup et al., 2014; Pollard et al., 2014). Potentially more important than peer social presence, instructor social presence requires further investigation into its implications for student engagement and outcomes, as well as methods for conveying it in the online classroom (Phirangee et al., 2016).

Swan and Shih (2005) were among the first to demonstrate statistically significant findings which indicated that peer social presence and instructor social presence were, in fact, two separate constructs. Their research suggested that an instructor's social presence was more important for perceived student satisfaction and learning than peer social presence. In their research, Swan and Shih (2005) addressed the instructor's expression of the social presence construct only. They found that an instructor's social presence was important for student engagement in online discussions. The study indicated that instructor social presence and teaching presence could help foster the social presence of students in online courses. Essentially, an instructor's social presence and teaching presence may create an environment that encourages students to demonstrate their social presence and build a community of learning (Bowers \& Kumar, 2015; Phirangee et al., 2016; Swan \& Shih, 2005).

Shea et al. (2010) investigated the role of social presence and teaching presence for both the instructor and the student in online courses. Their findings indicated that instructor social presence was essential for the development of student social presence, even more so than 
instructor teaching presence (Shea et al., 2010). These results are important when designing an online course, as they suggest that students will be more likely to demonstrate social presence and create a community of learning when instructors model and encourage social presence themselves (Shea et al., 2010). Determining how to best model social presence in online classes may be important for encouraging student social presence, which may increase student participation (Bowers \& Kumar, 2015).

The need for instructors to understand how to facilitate instructor social presence in online classes may be even more important in today's learning environment, as institutions routinely have courses taught by instructors who did not design them (Richardson, Besser, Koehler, Lim, \& Strait, 2016). Richardson et al. (2016) described the instructor's ability to impart their presence in a course as imperative for fostering student engagement, success, and satisfaction. Qualitatively, it has been shown that instructors feel their presence significantly impacts student outcomes in online courses where they did not design the content. Unique to Richardson et al.'s (2016) study is that instructors felt their presence enhanced student participation in online courses. These findings further support the essential role of instructor social presence in online teaching and learning.

Instructor social presence was also explored by Pollard, Minor, and Swanson (2014) who also found the construct to be an essential component of online learning, so much so that they suggested it be its own component of the COI framework. The study by Pollard et al. (2014) led to a deeper understanding of instructor social presence and a means for measuring the new variable through a Likert survey. Measuring peer social presence, teaching presence, instructor social presence, classroom community, and learning environment, using a Likert scale survey, the authors determined that instructor social presence was a separate construct, which can be 
independently measured. While instructor social presence did correlate highly with teaching and social presence, the redundancy did not reach an unacceptable level. Through instrument validation, the items created to measure instructor social presence loaded on a single factor, indicating that the construct could be measured as a separate concept. The study also showed that both peer and instructor social presence were essential for increasing the feelings of a classroom community among students, but in this case, teaching presence was not a significant predictor. All three presences were significant predictors of establishing a productive learning environment. Through their study, the researchers developed a valid and reliable method for measuring instructor social presence and further proved the importance of instructor social presence for the development of the student learning experience in online courses (Pollard et al., 2014).

Phirangee, Epps, and Hewitt (2016) also found a significant link between the instructor's role in online classes and student's development of classroom community and participation. Based on a study comparing peer-facilitated versus instructor-facilitated online discussions, students showed a significant preference for instructor involvement. The peer-facilitated course included mostly peer social presence and peer teaching presence, while the instructor-facilitated course included peer and instructor, social and teaching presence. The authors noted that instructor participation allowed students to feel their views and ideas were valued, and the instructor was invested in the course. Students in the instructor-facilitated course consistently participated at higher levels than the peer-facilitated course. Based on qualitative feedback and examination of student activity, the authors found students in the instructor-facilitated courses were more concerned with helping their peers learn and creating peer social connections, while those in the peer-facilitated course were concerned with meeting the requirements for engagement and their own learning. Phirangee et al.'s (2016) findings further supported the 
results of Shea et al. (2010) which indicated that peer social presence could be developed through instructor social presence. This research again established that instructor social presence is an important construct to consider when designing an online course that fosters student participation and engagement (Phirangee et al., 2016; Shea et al., 2010). These findings help confirm instructor social presence is an important factor in the participation of students in online discussions.

Instructor social presence, while considerably under-evaluated in the current literature compared to other components of the COI, has been shown to be increasingly important in the online learning environment (Lowenthal, 2016). The role of the instructor in developing classroom community, student engagement, and student retention has been well established (Bowers \& Kumar, 2015; Byrd, 2016; K. Swan \& Shih, 2005). The focus of the current study is to understand the specific impact of instructors' social presence on the development of student engagement, and how to best convey instructor social presence to students. Instructor social presence is becoming a more prominent issue in online learning as colleges and universities work to find solutions to online course retention problems as enrollment continues to rise.

\section{Summary}

This literature review described the impact of asynchronous video, student engagement, and instructor social presence on student outcomes in online learning. The focus on a possible connection between the three variables of asynchronous video, instructor social presence, and student engagement, which has been indicated in the research but not explicitly investigated, was described. The need to understand how asynchronous video technology can impact the development of instructor social presence in an online course, and how this development affects student engagement, is essential for creating better online teaching practices. One consequence 
of the current study is understanding a way to improve student engagement in online learning, by increasing instructor social presence and decreasing student feelings of isolation, which may lead to decreased student attrition.

This review clearly indicated a gap in the current understanding of how instructor social presence can influence student engagement, and the possibility of using technology to achieve student engagement goals through the development of instructor social presence. Through an understanding of the historical evolution of online learning and multiple perspectives on adult learning theory, it is clear that student engagement is a critical factor in online student success. This study aimed to continue the research of Borup et al. (2014) which indicated mixed results on whether asynchronous video could increase student perceptions of instructor social presence in a blended classroom. It was important to move beyond the assumption that instructor social presence may be the mediating factor in how asynchronous video has been able to increase student engagement, and provide quantitative data to support the conclusions of previous researchers. 


\section{Chapter 3: Research Methods}

Asynchronous video has been shown to be beneficial for enhancing student outcomes in online learning, possibly due to the increased presence of the instructor in the course, and the humanization of the learning experience (Borup et al., 2014; Glazier, 2016). Cultivating the student-teacher relationship through improved instructor social presence, as afforded by asynchronous video, is important for encouraging student engagement (Borup et al., 2014; Bowers \& Kumar, 2015; Draus et al., 2014; Glazier, 2016; Kushnir \& Berry, 2014).

Building on Kahu's (2013) student engagement framework and the COI theory of Garrison et al. (2000), this quantitative, quasi-experimental study aimed to clarify the use of asynchronous video as a means for increasing students' perceptions of instructor social presence and student engagement in an online course. Investigating the effect of asynchronous video versus text-based instructor announcements on students' perceptions of instructor social presence and student engagement addressed the problem of the current study. There was a need to determine whether asynchronous video can increase students' perceptions of instructor social presence and student engagement in online learning to impact retention and student learning outcomes. Student engagement and the instructor-student relationship have a positive impact on decreasing issues of retention (Byrd, 2016; Tinto, 1997). Retention issues are prevalent in online learning and are typically attributed to feelings of isolation and a lack of connection to the learning community (Byrd, 2016; McMahon, 2013; Rovai, 2002; Tinto, 1997). Unique to this study was the investigation of the role instructor social presence plays in developing student engagement, and the quantitative nature of the research.

The research questions generated non-directional hypotheses based on previous research. Literature has supported a positive relationship between asynchronous video, student 
engagement, and instructor social presence, but limited quantitative data exists to support the claims and makes the research insufficient for developing directional hypotheses.

RQ1: Does instructor use of asynchronous video change students' perceptions of instructor social presence in an online occupational therapy course?

RQ2: Does instructor use of asynchronous video change student engagement in an online occupational therapy course?

\section{Hypotheses}

H10 There is no statistically significant difference in the level of perceived instructor social presence based on instructor use of asynchronous video.

H1a There is a statistically significant difference in the level of perceived instructor social presence based on instructor use of asynchronous video.

H20 There is no statistically significant difference in the level of student engagement based on instructor use of asynchronous video.

H2a There is a statistically significant difference in the level of student engagement based on instructor use of asynchronous video.

\section{Research Methods and Design}

The researcher chose a nonequivalent group, post-test, quasi-experimental, quantitative design. The quantitative design was chosen for its ability to explain the relationship between the variables based on a research problem derived from observed trends in the field (Creswell, 2014). This type of design was chosen over mixed-methods or qualitative based on the previous research conducted in this area. Prior research on the variables of asynchronous video, instructor social presence, and student engagement, have been primarily based on qualitative and mixedmethods designs. Specifically, Borup et al. (2014) indicated that quantitative data in the study 
did not suggest a significant impact of asynchronous video on instructor social presence. However, qualitative data implied there was a significant effect. Most studies on the implications of asynchronous video on student engagement have been mixed or qualitative in nature.

Apart from Draus et al. (2014) which used count data of student discussion posts to measure student engagement and found a significant difference indicating asynchronous video may increase student engagement, studies have relied on student qualitative responses, coding of discussion posts, and self-report surveys to measure engagement (Dixson, 2015). Unique to this study was the emphasis on quantitative data to support or refute the qualitative findings and assumptions from past research, which concluded that instructor social presence may be a mediating factor between the positive effects of asynchronous video on student engagement (Borup et al., 2012; Bowers \& Kumar, 2015; Ma et al., 2015).

A quasi-experimental design was appropriate because the experimental and control group were not randomly assigned but were naturally formed by learner enrollment in one of the sections of an introductory online course at the host university. While a quasi-experimental group design did create selection threats to validity that were not controlled for, the setting did not allow for the formation of artificial groups, and thus required the researcher to use predetermined, self-enrolled cohorts for this study (Creswell, 2014). The present study used a quasi-experimental, quantitative design to evaluate the effect of asynchronous video versus textbased instructor announcements on student's perceptions of instructor social presence and student engagement in an online course.

Qualitative and mixed-methods designs were not selected for this study based on the research questions and hypotheses. Prior research has indicated that a predictable and directional effect of the independent variable on both dependent variables might be present based on 
qualitative data. Quantitative data was needed to support the noticeable impact of one variable on another through numerical data and statistics, and was not based on the interpretation of participants' feelings and opinions (Creswell, 2014). The problem of using technology to impact student engagement has been well studied through qualitative design, and an understanding of the impact of asynchronous video on student engagement has been described (Borup et al., 2011, $2012,2014)$. The current need was for quantitative data to support the qualitative assumptions made by previous researchers.

One experimental group received twice weekly video-based, instructor-generated announcements, and one control group received twice weekly, text-based, instructor-generated announcements, through the learning management software (LMS) over a 10-week period. In all groups, the dependent variable of instructor social presence was measured through a Likert scale electronic survey, and the dependent variable of student engagement was measured by the number and length of student posts, on voluntary weekly discussion forums. Data was analyzed using a multivariate analysis of variance (MANOVA) statistical test. The researcher was aware that the low number of participants in the study may mean the assumptions of the MANOVA would not be met and therefore, a non-parametric Kruskal-Wallis test was performed in addition to the MANOVA (Finch, 2005).

The researcher understood the limitations and delimitations of the present study. The study was conducted in a Masters of Occupational Therapy program, using a foundational occupational therapy course, which limited the generalizability of the findings to students in other fields of study or levels of education. However, the research questions focused on the dependent variables of instructor social presence and student engagement, which allowed for generalization to other online courses since course content and performance were not the focus 
of the research (Trochim \& Donnelly, 2007). A small sample size and inherent differences between the two groups requires readers to utilize the results of the study with caution.

This study was conducted in the spring 2017 term, in two sections of a first term course, required as part of a Masters of Occupational Therapy (MOT) program at the University of St. Augustine for Health Science. The course, OCT 5140-Domain of Occupational Therapy, is a foundational course covering basic history, framework, and theories relevant to the occupational therapy profession. The course was co-taught by licensed occupational therapists and educators who had previously delivered this content in a different format or course. The lead instructor for both sections was the same professor, and this was also the person who delivered the bi-weekly announcements, both text and video-based. The lead instructor also facilitated the voluntary discussion forums. The course syllabus, grading, content, and expectations were the same for both sections of the course. Online materials, except for announcements, were delivered in a similar manner between the two courses and were not designed by the lead instructor.

And as mentioned by Richardson et al. (2016) more frequently in online education, instructors are not teaching courses they developed, minimizing the instructor's inherent teaching presence and requiring a need for increased deliberate instructor social presence to help create a sense of classroom community. Every attempt was made to control for similarities in the delivery of the course, other than the independent variables of asynchronous video and text-based communication used during structured instructor announcements. Quantitative data was collected to analyze the impact of asynchronous video technology on students' perceptions of instructor social presence and student engagement. 


\section{Population}

The population of interest consisted of online graduate students enrolled in one of two sections of a MOT course during the spring 2017 term. Student background information was not accounted for in this study and may be a delimitation of the research. All students in this population were first-term students enrolled at the St. Augustine, Florida campus in either the campus-based program (Group A) or Flex program (Group B). The Flex program required students to take their didactic coursework online during the week and attend labs on weekends. Both the campus-based and Flex programs required students to take blended and fully online courses; the proportion of fully online and blended learning is higher in the Flex program than the campus-based program. All participants met the admissions criteria for the institution before enrolling in the course. Learners were automatically enrolled in the section of the course that corresponded with their program delivery format, campus-based (Group A) and Flex (Group B).

The Flex program closely models an online program, and thus tends to attract more nontraditional students. While demographic data was not collected for this study, research has indicated that students who enroll in the online programs tend to be non-traditional students (Xu \& Jaggars, 2013). These students are usually older, and have non-academic responsibilities such as work or family (Ortagus, 2017; Xu \& Jaggars, 2013). The inherent differences between the Flex and campus students was a limitation of this study and may be a confounding variable that was not accounted for in the research. Participants were required to be enrolled for the first time at the University of St. Augustine.

\section{Sample}

Through G-Power analysis it was determined that 22 participants would be necessary to achieve a power of .80. This is considered acceptable for studies and indicates a high level of 
power, reducing the chance of experiencing a type-II error (Hatcher, 2013). G-Power analysis was conducted assuming a MANOVA test would be run on the data, an alpha level of .05 was used, and an effect size of .67 was determined through G-Power analysis based on a Pillai V of .40 , with two groups and three response variables. There were 33 students enrolled in the campus-based section of the course and 12 in the Flex section in the spring of 2017. Based on a sample size of $45,48.9 \%$ of students needed to provide consent to participate in the study to achieve a power of .80 in this study. A total of 39 students provided consent to participate in the study. Twenty-nine campus-based students and 10 Flex-based students consented to participate in the research. This study had a high dropout rate in the campus-based section of the course. Sixteen participants, or $55 \%$, of the students from the campus program did not participate in any portion of the research and were dropped from the study due to non-participation. One participant from the Flex program did not participate and was dropped from the study due to non-participation. The sample size to achieve power for a MANOVA was met with the 22 participants who completed the study.

\section{Materials}

All participants took part in the course through the LMS Blackboard system. The instructor utilized video recording software and embedded the bi-weekly videos directly into the course announcement page to prevent students from having to access a separate website to obtain the information. Other course content, including readings, assignments, audio presentations, and text-based information, was presented in the same way to both cohorts through the coursework and unit tabs within the LMS platform. This content, including the audio presentations, was developed by instructors not involved in the current course. Voluntary discussions took place 
within the LMS course. Students were required to have access to a computer to participate in the course.

\section{Operational Definition of Variables}

Type of communication. The independent variable type of communication was a categorical variable with two levels, asynchronous video and text-based communication. Asynchronous video was defined as communication using embedded software that allowed students to see and hear the instructor provide information. Text-based communication referred only to typewritten communication with no audio or visual cues from the instructor. Text-based communication included all alphanumeric characters, punctuation, and emoticons. The study focused on twice weekly announcements in the course and did not contain any other asynchronous communication such as assignment feedback, email messages, and course content.

Instructor social presence. The dependent variable, instructor social presence, was measured using a Likert scale, the Instructor Social Presence survey. (See Appendix B.) Developed by Pollard, Minor \& Swanson (2014) the Instructor Social Presence survey was part of a larger instrument designed, tested, and used by the original researchers. These researchers established a Cronbach's alpha of .93, indicating a high level of internal consistency in the items assessing instructor social presence, and determined an exploratory factor analysis on these items ranging from .810-.928, which established a high level of single factor loading (Pollard et al., 2014). Though this study was the only research to use this scale, it was deemed appropriate for use in the current research due to the high internal consistency and inter-relationship among test items, indicating a good representation of instructor social presence. Data obtained from this survey was considered ordinal data (Hatcher, 2013). 
Student engagement. This dependent variable was measured in two ways and provided ratio data for two response variables. Student engagement was measured as the number of posts made by a student in a voluntary discussion forum and the length of posts, determined by the total characters. Per Kahu's (2013) student engagement framework, participation, time and effort, and interaction were listed as the behavioral manifestations of student engagement. Additionally, Dixson (2015) stated that student engagement required the students to devote time and energy to the course and demonstrate their learning through interaction with others. The amount of student discussion forum posts and length of posts, therefore, indicates the willingness of students to devote time and energy to the course by participating in interactions with course mates and instructors. Previous researchers have utilized discussion post counts and character counts as a means of measuring student engagement (Draus et al., 2014).

Unique to this study was the use of voluntary discussion forums to measure student engagement. The fact that the discussion posts were optional indicated a new level of student engagement, not previously investigated. Voluntary participation required the students to be intrinsically motivated to participate and may represent the cognitive, and affective components of student engagement, which were previously measured through self-report surveys and qualitative means only (Dixson, 2015; Kahu, 2013). The affective dimension of student engagement was defined by the students' interest, enthusiasm, and sense of belonging (Kahu, 2013). The cognitive dimensions represent the deep learning and self-regulation associated with student engagement and included the motivation, goals, and self-efficacy of students (Kahu, 2013). Students who were more affectively and cognitively engaged presented with a masteryoriented approach to learning which focuses on the intrinsic rewards of learning, rather than a performance orientation which focuses on being rewarded by grades or outside 
acknowledgement of efforts (Handelsman, Briggs, Sullivan, \& Towler, 2005). The importance of affective and cognitive engagement is emphasized in the student engagement literature, but has been challenging to measure (Kahu, 2013). Utilizing a count of voluntary discussion posts and evaluating the length of posts, this study measured student engagement from a behavioral, affective, and cognitive standpoint.

\section{Data Collection and Analysis}

All data collection was done through the host institution, the University of St. Augustine for Health Sciences, St. Augustine campus. The University of St. Augustine Institutional Review Board (IRB) approved the quasi-experimental study prior to data collection. (See Appendix C.) One first term Masters of Occupational Therapy (MOT) course was chosen for the study. This course was selected because there were two concurrent sections of the course available and it was a first term course. This may have helped reduce student bias since students had not been previously enrolled in an online course with the instructor.

Throughout the course, the experimental cohort (Group A) received all instructorgenerated announcements via asynchronous video displaying both the visual and auditory presence of the instructor. The control cohort (Group B) received all instructor-generated announcements via text. The same lead instructor facilitated both sections of the course in the BlackBoard Learning Management System (LMS). The course was run in spring 2017 using the same course content, assignments, syllabus, and schedule. Students were not randomly assigned to a section of the course, which was a limitation of this study. The independent variable, asynchronous video or text-based communication, was randomly selected for each section of the course. Face-to-face contact with the researcher was limited in all sections to avoid carryover. 
When an occasional need arose for individual student interaction, co-instructors handled any necessary meetings with students via video chats or in-person conferences.

For 10 weeks, each cohort received an announcement tailored to the class, once early in the week and once near the end of the week, with weekly cycles of Monday through Sunday. While the announcements were tailored to the individual needs and participants of the cohort, the announcements maintained the same specific format, regardless of the course section. (See Appendix D.) Announcements were provided for weeks 2-10, with a Likert scale survey electronically delivered to participants who provided consent to participate in the research study, during Week 10 of the course. Both sections of the course received an audio-only introduction including an overview of the syllabus, schedule, and information about the current research study being conducted within the course. Audio explanations about the research study with a request for participants and the approved informed consent were sent to students during Week One of the course. If the need arose during the course to communicate with students beyond the scheduled course announcements, a text-based email communication was sent to the class. Individual feedback on assignments and all other course communication were completed through text and via other tools within the LMS except for announcements such as email and assignment feedback.

During each announcement, in both sections, the instructor reminded students of the voluntary discussion forum taking place during Weeks 5-10. The researcher chose to measure six of the 14 weeks of content in the middle of the term to capture the typical participation of a student. Student participation in online discussion tends to wane as the course moves past midterm (Xie, Durrington, \& Yen, 2011). Since the students were also new to the program and the LMS, the researcher chose to wait until students were comfortable with the learning platform and 
course layout before introducing voluntary discussion posts. These six consecutive mid-term weeks were chosen for voluntary discussion forums to capture the students' true willingness to engage in the course and reduce the co-variates of comfort level with technology, and time in the course. All students were able to take part in the discussion forums, regardless of their consent to participate in the research, though only those who consented to participate had their posts counted for data collection purposes.

The discussion forum was facilitated by the lead instructor through text-based prompts, article links, or videos created by others. The discussion forum was started by a weekly prompt created by the lead instructor, and discussions within the forum were facilitated and moderated by the lead instructor. Material presented in the voluntary discussions was related, but ancillary to, the course content. Participation or lack of participation in the voluntary discussion forums did not impact a student's ability to be successful in the course. The discussion forum was run within the LMS course for ease of access, with a link embedded in the corresponding course unit. The same prompts were used for each of the six weeks, for both groups.

Due to the inability of the researcher to create artificial groups, all students enrolled in either section of the course were subjected to the experimental or control conditions. Students were informed of the study through an audio-only announcement on the first day of the course and provided a University of St. Augustine for Health Sciences IRB approved informed consent form. All willing participants were asked to return the signed consent form after all questions had been addressed, if they chose to participate. While all students received the experimental or control condition, only those who consented to participate in the study received an electronic Instructor Social Presence scale through SurveyMonkey during Week 10 of the course. Also, only those who consented to participate had their voluntary discussion forum posts counted 
during Week 10 of the course. SurveyMonkey was chosen for electronic delivery of the Instructor Social Presence scale as it allowed for participant convenience in completing the survey.

The researcher tested the data through a one-way, between-subjects MANOVA.

MANOVA was chosen for this data because the study involved an independent variable, a type of communication which was a categorical variable with two groups, asynchronous video, and text. There were two dependent variables, instructor social presence which is an ordinal variable, and student engagement, which was measured in two ways and provided ratio data. A reasonable correlation among the dependent variables existed. It was assumed that the participant's perception of instructor social presence and student engagement was independent of any other participant.. While Likert-type items are considered ordinal data, it is acceptable to utilize Likert scale data, or the composite score of four or more Likert-type items as interval data, making the instructor social presence survey total appropriate for parametric statistics (Boone \& Boone, 2012).

Choosing a MANOVA was appropriate given the need to determine whether asynchronous video could impact student engagement, while at the same time examining the potential correlation between instructor social presence and student engagement as suggested in the literature (Borup et al., 2014). A MANOVA also allowed for detection of differences on two dependent variables at once, which reduced the chance of Type I errors resulting from repeated statistical analysis (Hatcher, 2013). Aside from independence, a MANOVA also assumes normality and homogeneity of covariance (Hatcher, 2013). Due to the small sample size, the researcher acknowledged that there may have been a violation of these assumptions and conducted a non-parametric statistic, the Kruskal-Wallis test, to adjust for these violations 
(Finch, 2005). The Kruskal-Wallis is an appropriate, non-parametric alternative to a MANOVA when assumptions of normality and homogeneity are not met. The Kruskal-Wallis test is a variation of the one-way ANOVA, which is the post-hoc test for the MANOVA (Finch, 2005). Additional post-hoc tests were conducted based on the results of the statistical tests, as appropriate.

\section{Assumptions}

There was a basic assumption in this study that the primary researcher and lead instructor honestly carried out their responsibilities and maintained neutrality throughout the study, thereby conducting the study in an unbiased manner. An additional assumption was that students were provided one type of communication with the instructor, video or text, throughout the course so that results could properly show an association between type of communication and instructor social presence and student engagement. Students were also assigned to the section of the course that corresponded to their program, eliminating sampling bias.

This study also assumed that the Instructor Social Presence scale and a count of participation in a voluntary discussions based on total number and length, were true indicators of students' perceptions of instructor social presence and student engagement. Additionally, the study assumed that learning styles, age, and other demographic variables associated with the individual participants did not affect student engagement and perceptions of instructor social presence. If all assumptions were met, it could be concluded that the results of the study indicated whether a true relationship between type of communication and instructor social presence and student engagement existed.

There were additional assumptions made for using the MANOVA analysis. It was assumed that the independent variable of type of communication had two groups, asynchronous 
video and text-based. The assumption was also made that the students' engagement and results on the Instructor Social Presence scale were independent from each other. The assumption of normality of the data was not met based on a Shapiro-Wilk test of normality. Homogeneity of covariance was also not met based on the Box's Test of Equality of Covariance. According to Finch (2005), the MANOVA is robust to violations of the assumptions of normality and homogeneity. A MANOVA may be just as powerful and resistant to Type I error as a nonparametric alternative. Based on a low sample size, the researcher chose to conduct the suggested non-parametric alternative to the MANOVA to confirm statistical significance among results (Finch, 2005).

\section{Limitations}

Limitations of the study included sample size and unavoidable variations within the design of the courses. The maximum number of students enrolled in each section could not exceed 50 combined. Due to uncontrolled enrollment issues, fewer students were admitted to the Flex program than originally anticipated. These changes reduced the overall population size from which the sample was drawn. Additionally, though 39 students consented to participate, there was a high attrition rate from the study for students in Group A. There was a 55\% attrition rate from group A and a 10\% attrition rate from Group B, reducing the total sample size of students to 22 participants. However, this was an adequate number of participants to conduct the study according to G-Power analysis at a power of .80 .

There were also inherent differences between Group A and Group B students, which may have been a limitation of this study. While both groups were taking this course fully online and all students were in a blended program, the campus students received more of their coursework face-to-face than the Flex students throughout the program. The University of St. Augustine 
defines the Flex program as containing a combination of laboratory/online courses. The didactic material is offered online with lab sessions held face-to-face on the weekends (University of St. Augustine for Health Sciences, 2016).

Students in the Flex program were also enrolled in fewer course credits per term than most campus students. Flex students tended to be more non-traditional than their campus counterparts and may have been more prepared for an online program based on the University Catalog description (University of St. Augustine, 2016a). Campus students tended to resemble more traditional student demographics of an age under 25 and participated in education full time (Ortagus, 2017). They also may have anticipated participating in a program that was blended, with a high proportion of courses conducted face-to-face based on the history of the program and the University Catalog description (University of St. Augustine, 2016a). Until the spring 2017 term, campus students received more of their education in traditional or web-enhanced courses. The shift to a blended program with a stronger emphasis on online learning may have been challenging for students enrolled in the campus program who were not prepared for a significant portion of the curriculum to be delivered in an online format. The demographic differences in students was not studied or accounted for in this research. Student expectations on course delivery format were also not evaluated in the current study.

Neither section of the course had previously been run in either program before spring 2017. Errors in course design may have impacted the way content was delivered in the two sections and initial issues in online course delivery may have impacted the way students participated in the course. An additional burden may have been placed on students due to the challenges in course design and delivery, which may have limited their desire to participate in non-required course activities. 


\section{Delimitations}

The lack of demographic data collected on the students made it challenging to generalize the data to other populations. The present study was conducted in an online, graduate, health science program which may make the findings generalizable to other similar institutions. The researcher chose to use a quantitative methodology for conducting the research instead of qualitative or mixed methods methodology due to the lack of quantitative data available on the topic. By not including qualitative inquiry, the researcher may not have developed a complete understanding of the complexity of the connection between asynchronous video communication, student engagement and instructor social presence. The researcher also chose to use the Instructor Social Presence survey developed by Pollard et al. (2014). This survey has not been used extensively, but it does have established reliability and validity in one previous study. Kahu's Student Engagement framework was chosen for this research based on its incorporation of the structural and psychosocial influences that contribute to student engagement and the multifaceted description of the construct as an affective, cognitive, and behavioral student outcome. Other student engagement frameworks contributed to the understanding of this construct but were more narrowly focused (Dixson, 2015; National Survey of Student Engagement, 2016). The delimitations of this study may have impacted the researcher's ability to interpret or generalize the results.

\section{Ethical Assurances}

This research was conducted adhering to all standards for conducting research using human participants. There was minimal risk to the subjects because they received the same instruction they would if they were not participating in a course where research was being conducted. The benefits of understanding the impact of asynchronous video and text-based 
communication on student engagement and the role of instructor social presence are essential for the success of online students. All informed consents forms were sent directly to the researcher. The researcher acquired permission from the University of St. Augustine's IRB committee to carry out the study before initiation of the research.

\section{Summary}

The purpose of this quasi-experimental, quantitative study was to determine the impact of asynchronous video and text-based communication in an online occupational therapy class on the development of students' perceptions of instructor social presence and student engagement. The research methods used for this study required the use of a MANOVA statistical test to determine whether an association between the independent variable, type of communication (video or text), and instructor social presence and student engagement existed. Though the MANOVA is robust to violations of assumptions, the Kruskal-Wallis non-parametric test was also conducted due to the small sample size. The independent variable was type of communication, which included two levels, asynchronous video and text-based. The dependent variables were student engagement, measured by discussion post and length, and students' perceptions of instructor social presence.

The researcher was granted permission for this research from the University of St. Augustine, a small, private, graduate, health science school. The University is currently in the process of converting many of its courses into hybrid or online formats for instruction. The data was analyzed in hopes of yielding quantifiable results that could aid instructors and institutions in utilizing technology to enhance student engagement and reduce issues of retention in online courses. 


\section{Chapter 4: Findings}

The purpose of this quasi-experimental, quantitative design study was to determine the effect of asynchronous video as compared to text-based communication on instructor social presence and student engagement in an online graduate course. The hypotheses used were nondirectional because previous studies have not established a clear or direct relationship between asynchronous video, instructor social presence and student engagement, in fully online courses. Although the use of asynchronous video as a method of increasing instructor social presence and student engagement have been separately examined in the literature, previous studies have used qualitative and mixed-method designs only, with varied results on the effectiveness of this technology (Borup et al., 2014; Glazier, 2016; Zak, 2015). The primary research intent for the current study addressed student perceptions of instructor social presence based on one dependent variable measure, ratings on the Instructor Social Presence survey. The research also addressed student engagement based on two dependent variable measures: 1) number of posts in voluntary student discussion boards, and 2) length of posts in voluntary student discussion boards. The independent variable, type of communication, had two levels, asynchronous video and textbased. The combination of measuring asynchronous video and the impact on both instructor social presence and student engagement, as well as the use of voluntary discussion boards as a measure of student engagement, makes the present study unique to previous research.

The participants of the present study all attended the University of St. Augustine for Health Sciences, Masters of Occupational Therapy (MOT) program. IRB approval and permission from the host university was obtained before conducting the study in the spring of 2017. A Multivariate Analysis of Variance (MANOVA) was used to analyze the data. Prior to conducting the analysis, the data was examined to determine whether there was any missing data due to the limitations of MANOVA. Out of $\mathrm{N}=36$, only $\mathrm{N}=22$ were useable for the MANOVA 
tests due to missing values on the instructor social presence and student engagement measures. Group A had 13 participants and Group B had 9 participants. The primary data missing was the Instructor Social Presence survey. Missing data would have needed to be replaced with a zero, which was not a mathematical possibility based on the scale of the survey, and would have skewed the data. Fortunately, according to G-Power analysis, only $\mathrm{N}=22$ was necessary to achieve a power of .80, and an alpha of .05.

Preliminary MANOVA assumption testing was conducted to check for multivariate normality and homogeneity of covariance. Due to the small sample size, a few of the assumptions of the MANOVA were not supported. These included normality, which was tested using the Kolmogorov-Smirnov Test, Homogeneity of covariance matrices, using Box's Test, and equality of error variances using Levene's Test. The number of student posts for Group A, $D(13)=.453, p=.000$, the length of student posts for Group A, $D(13)=.451, p=.000$, and the length of student posts for Group B, $D(9)=.333, p=.005$, were statistically significant for the test of normality indicating that they violated the assumption of normality for the MANOVA. The Box's Test was also significant, $p=.004$, indicating that the data did not meet the homogeneity of covariance matrices. Based on the Levene's Test, equality of error variances was rejected for the number of student postings, $\mathrm{F}=16.829, p=.001$, and length of student posting, $\mathrm{F}=15.620, p=.001$.

Finch (2005) suggested that the MANOVA is robust to violations of assumptions, including homogeneity and normality, especially when group sizes are relatively equal which was the case in this research. Relative equality in sample sizes includes groups that are no more than twice as large as the smallest group (Field, 2009). While the MANOVA analysis is appropriate for this research based on the robust nature of the test and the relatively equal sample 
sizes, the researcher suggests the results should be considered cautiously. The researcher acknowledged that the small sample size may have impacted the results of the statistical analysis and chose to perform the non-parametric Kruskal-Wallis test to adjust for these violations (Finch, 2005).

The Kruskal-Wallis test is the non-parametric alternative to the one-way ANOVA and is the preferable alternative when the assumptions of the parametric statistical test are not met (Finch, 2005). The Kruskal-Wallis is an appropriate test for data that violates assumptions of normality and homogeneity of variance. As the one-way ANOVA is the appropriate post-hoc analysis for a significant MANOVA test, the Kruskal-Wallis is the appropriate alternative to the MANOVA test as well. In previous research Finch (2005) determined the MANOVA and Kruskal-Wallis tests retained relatively similar power and type I error rates in most scenarios. The Kruskal-Wallis does not assess the relationship between multiple dependent variables however, which was a major objective of this study (Finch, 2005).

MANOVA was used to investigate the impact of type of communication, asynchronous video versus text-based communication, on students' perceptions of instructor social presence and student engagement. Three dependent variables (DVs) were used: students' perceptions of instructor social presence (ISP) and student engagement (SE), which was measured by number of discussion posts (NP) and length of discussion posts (LP). The independent variables (IV) included type of communication (COM), asynchronous video (AV) and text-based communication (TB). The Kruskal-Wallis test was used to investigate all of the same DVs and IVs. Although the assumptions of the MANOVA were not fully met, the researcher finds it applicable and necessary to include the data analysis using the MANOVA and Kruskal-Wallis tests, with a recommendation to consider the results cautiously. 


\section{Results}

The research questions were designed to determine the effect of the IV, type of communication in an online course, on the two DVs, perceptions of instructor social presence and student engagement. The present study offered new research concerning the IVs and DVs. The impact of the IV has been studied in online courses with mixed results regarding its effectiveness for impacting student outcomes (Borup et al., 2011; Kushnir \& Berry, 2014; Zak, 2015). Unique to this study was the investigation of the IV in relationship to both DVs, where most previous research discussed the connection between the DVs but had not specifically tested the assumptions (Draus et al., 2014; Glazier, 2016). The DV, student engagement, was also measured using voluntary discussion boards which is unique to this study and was utilized to investigate this DV from an affective, cognitive, and behavioral perspective.

Previous research has utilized self-report measures and participation in mandatory discussion boards as a determination of student engagement, both of which are subject to bias (Dixson, 2015; Draus et al., 2014). The DV, instructor social presence, was measured using a Likert scale survey. While the majority of research related to this construct has utilized qualitative analysis of student comments to determine whether instructor social presence was perceived in an online classroom, the current study focused on quantitative analysis (Borup et al., 2014; Richardson et al., 2015). For the purpose of the present study, one course section received asynchronous video communication and the other received text-based communication.

The findings explored the unique relationship between types of communication, instructor social presence, and student engagement. The limited population from which the study sample was drawn, and the small number of participants, makes it a challenge to generalize the results across other populations. The multivariate result was significant for type of communication, Pillai's Trace $=.411, F=4.185, d f=(3,18), p=.021, \eta_{2}=.411$, indicating a 
difference in the level of student engagement and instructor social presence between those who received asynchronous video and those who received text-based communication. Table 1 shows the univariate analysis for each of the variables in the current study.

Table 1

Summative Analysis of Univariate Statistics

\begin{tabular}{|c|c|c|c|c|c|c|}
\hline Source & Dependent Variable & $\begin{array}{c}\text { Type III Sum of } \\
\text { Squares }\end{array}$ & df & Mean Square & $\mathrm{F}$ & Sig. \\
\hline \multirow[t]{3}{*}{$\begin{array}{l}\text { Type of } \\
\text { Communication }\end{array}$} & Number of Posts & $79.724^{\mathrm{a}}$ & 1 & 79.724 & 11.132 & .003 \\
\hline & Length of Posts & $26670460.030^{\mathrm{b}}$ & 1 & 26670460.030 & 7.636 & .012 \\
\hline & ISP Score & $34.732^{\mathrm{c}}$ & 1 & 34.732 & 2.410 & .136 \\
\hline
\end{tabular}

a. $\mathrm{R}$ squared $=.358$

b. $\mathrm{R}$ squared $=.276$

c. $\mathrm{R}$ squared $=.108$

After analysis of the data, a significant difference in student engagement for NP and LP was found, based on type of communication.

Since the assumptions of the MANOVA were not fully met, the researcher conducted a Kruskal-Wallis test to validate the findings. Table 2 depicts the findings from the Kruskal-Wallis test.

Table 2

Kruskal-Wallis Summative Analysis

\begin{tabular}{lccc}
\hline \multicolumn{1}{c}{ Test Data } & Number of Posts & Length of Posts & ISP Score \\
\hline Chi-Square & 9.476 & 8.352 & 1.921 \\
df & 1 & 1 & 1 \\
Asymp. Sig. & .002 & .004 & .166 \\
Exact Sig. & .001 & .003 & .175 \\
Point Probability & .000 & .001 & .011 \\
\hline
\end{tabular}

After analysis of the data, a significant difference for student engagement was found based on the exact significance for NP and LP. Exact significance was used because the sample size was less than $\mathrm{N}=40$ (Field, 2009). The researcher suggests the findings be used cautiously due to the 
violations of the assumptions for the MANOVA statistical test, though the Kruskal-Wallis test further confirmed the results of the MANOVA.

The first research question investigated the effect of asynchronous video on students' perceptions of instructor social presence in an online occupational therapy course. The null and alternate hypotheses were used to investigate the question.

RQ1: Does instructor use of asynchronous video change students' perceptions of instructor social presence in an online occupational therapy course?

H10 There is no statistically significant difference in the level of perceived instructor social presence based on instructor use of asynchronous video.

H1 a There is a statistically significant difference in the level of perceived instructor social presence based on instructor use of asynchronous video.

A MANOVA (see Table 1 above) was run for type of communication, and no statistically significant differences in student perceptions of instructor social presence were found, $\mathrm{F}(3,18)=$ 2.410, $p=.136$. A Kruskal-Wallis test (see Table 2 above) was run for type of communication, and no statistically significant differences in student perceptions of instructor social presence were found, $\chi^{2}(1)=1.921, p=.175$. The researcher concluded that there was no significant difference in the use of asynchronous video on student perceptions of instructor social presence; therefore, the null hypothesis was not rejected.

Research question two addressed the use of asynchronous video and the impact on student engagement in an online occupational therapy course. The amount of student engagement was measured using number of student posts and length of student posts, calculated by character counts without spaces, in a voluntary discussion board. The null and alternate hypotheses were used to investigate this question. 
RQ2: Does instructor use of asynchronous video change student engagement in an online occupational therapy course?

H20 There is no statistically significant difference in the level of student engagement based on instructor use of asynchronous video.

H2 $\mathbf{a}$ There is a statistically significant difference in the level of student engagement based on instructor use of asynchronous video.

A MANOVA (see Table 1 above) was run for student engagement based on NP. There was a statistically significant difference in the number of discussion posts based on type of communication, $\mathrm{F}(3,18)=11.132, p=.003$. Analysis of the Kruskal-Wallis data (see Table 2 above) indicated that a statistically significant difference existed for NP based on communication type, $\chi^{2}(1)=9.476, p=.001$. The MANOVA follow-up tests in Table 3 showed that the group who received text-based communication produced the highest mean number of discussion posts (4.333).

Table 3

MANOVA Results for Dependent Variables Based on the Type of Communication and Number of Discussion Posts

\begin{tabular}{lcccccc}
\hline Dependent Variable & $\begin{array}{c}\text { Type of } \\
\text { Communication }\end{array}$ & $\mathrm{N}$ & Mean & Std. Error & \multicolumn{2}{c}{$95 \%$ Confidence Interval } \\
& Asynchronous Video & 13 & .462 & .742 & Lower Bound & Upper Bound \\
\hline Number of Posts & Text-based & 9 & 4.333 & .892 & -1.087 & 2.010 \\
& & & & & 6.194 \\
\hline
\end{tabular}

After the data was analyzed, the researcher concluded that there was a significant difference in the number of discussion posts based on the type of communication.

A MANOVA (see Table 1 above) was run for student engagement based on LP, and it was found a statistically significant difference was found in the length of discussion posts based 
on type of communication, $\mathrm{F}(3,18)=7.636, p=.012$. Analysis of the Kruskal-Wallis data (see Table 2 above) indicated that a statistically significant difference existed for LP based on communication type, $\chi^{2}(1)=8.352, p=.003$. The MANOVA follow-up tests in Table 4 indicated that the group who received text-based communication produced the highest mean length of discussion posts (2661.333).

Table 4

MANOVA Results for Dependent Variables Based on the Type of Communication and Length of Discussion Posts

\begin{tabular}{lcccccc}
\hline Dependent Variable & $\begin{array}{c}\text { Type of } \\
\text { Communication }\end{array}$ & $\mathrm{N}$ & Mean & Std. Error & \multicolumn{2}{c}{$95 \%$ Confidence Interval } \\
& Asynchronous Video & 13 & 421.923 & 518.342 & -659.318 & Lower Bound \\
\hline Length of Posts & Text-based & 9 & 2661.333 & 622.969 & 1361.843 & 3960.824 \\
\hline
\end{tabular}

After the data was analyzed, the researcher concluded that there was a significant difference in the length of discussion posts based on the type of communication with the student. The researcher was able to determine that there is a statistically significant difference in student engagement based on the instructor's use of asynchronous video. Therefore, the null hypothesis is rejected. The alternate hypothesis is supported because the students who received asynchronous video had a decreased mean number of discussion posts and length of discussion posts $(\mathrm{M}=.462,421.923)$ compared to students receiving text-based communication $(\mathrm{M}=4.333$, 2661.333). Post-hoc analysis of data was not indicated because there were only two levels of the IV.

A Spearman's rho test was performed on the individual items of the Instructor Social Presence survey to determine if any differences between individual survey items occurred based on type of communication, which may help explain the unique study findings. One of the ten 
items did indicate a significant correlation between item and type of communication, $r_{s}=.469, p$ $=.028$. Type of communication was significantly correlated to the item "my instructor creates an attitude of sharing" (Pollard et al., 2014, p.9). Upon further analysis, it appears that those in the text-based group indicated a higher level of perceived attitude of sharing than those in the asynchronous video group $(\mathrm{M}=4.778, \mathrm{M}=4.231)$. No other correlations were significant between type of communication and items on the Instructor Social Presence survey.

\section{Evaluation of Findings}

Previous research has investigated the use of asynchronous video, separately identifying a potential increase in student perceptions of instructor social presence and student engagement in an online or hybrid course (Borup et al., 2014; Draus et al., 2014). Positive findings for improved student outcomes when using asynchronous video have primarily been based on qualitative comments from students (Borup et al., 2011, 2012, 2014). As student retention issues in online education continue to be a concern for institutions (Allen \& Seaman, 2014; McMahon, 2013), there is a need to determine whether asynchronous video is an appropriate method for impacting student engagement. Further understanding the complexity of the interaction between asynchronous video, instructor social presence, and student engagement is important.

The previous research has indicated a positive relationship between the use of asynchronous video and student engagement, with an assumption that the improvement in student engagement was due to increased instructor social presence afforded by the technology (Borup et al., 2014; Kushnir \& Berry, 2014; Mcdowell, 2011). These assumptions were made based on student comments, and the idea that asynchronous video increases humanization of an online course through the conveyance of immediacy behaviors. In turn, these immediacy behaviors can increase a student's sense of community and therefore student engagement (Baker, 
2010; Borup et al., 2011, 2014; Bowers \& Kumar, 2015; Glazier, 2016; Weiss, 2000). Direct investigation into this concept has not been conducted and is worthy of investigation. Borup et al. (2014) identified the need for further investigation into the connection between asynchronous video and instructor social presence, along with the impact of both on student outcomes. This research should be conducted with additional quantitative analysis, in an online classroom. The present study investigated the use of asynchronous video as a method of communication to increase instructor social presence in an online class and improve student engagement through quantitative means.

Research Question One. The first research question asked whether there was a difference in student perceptions of instructor social presence based on the use of asynchronous video communication. Through analyses of the data, no significant difference was found in student perceptions of instructor social presence based on the use of asynchronous video in an online classroom. A total of 13 students received asynchronous video and 9 received text-based communication. Although no significant difference was found in regard to the MANOVA, those who received text-based communication indicated slightly increased ISP $(M=47.56)$ compared to those who received asynchronous video communication $(M=45.00)$.

In an online classroom, it is important for students to perceive their instructors as real people in order to create the sense of community needed to improve the educational experience (Arbaugh et al., 2008; Lowenthal, 2016; Pollard et al., 2014). Determining how to effectively display instructor social presence to online learners is essential to building classroom community. As a result, students will benefit from the improved student engagement that develops because of the feelings of connection and support (Borup et al., 2014; Lowenthal, 2016; Richardson et al., 2015). Borup et al. (2014) indicated that through instructor and student 
comments, increased instructor social presence was conveyed through the use of asynchronous video better than through text-based communication. This finding was not supported through quantitative analysis however, and the researchers indicated that the lack of quantitative findings were due to the blended format of the course. Through data analysis the present study confirmed that no statistically significant difference could be determined for instructor social presence based on the type of communication students received, despite conducting the study in a fully online course. The present study only focused on quantitative data, so it is not clear whether a qualitative finding, similar to that of Borup et al. (2014), would have been found in the current study. Research has indicated that increased instructor-student rapport and quality communication through the use of asynchronous video are key to creating an atmosphere that supports students in an online classroom (Glazier, 2016; Kushnir \& Berry, 2014). The current study did not indicate that asynchronous video was any more effective than text-based communication for increasing student perceptions of instructor social presence in an online class.

Research Question Two. The second research question asked whether there was a difference in student engagement based on the use of asynchronous video communication. Through analyses of the data, a significant difference was found in student engagement based on the use of asynchronous video for both the number of discussion posts and the length of the discussion posts. There were 13 students in the group who received asynchronous video and 9 who received text-based communication. Students who received asynchronous video had significantly fewer total numbers of posts and length of posts than those who received text-based communication The mean number of posts for those who received asynchronous video was .462, while the mean number of posts for the group receiving text-based communication was 4.333 . 
The mean length of posts for those who received asynchronous video was 421.923 characters, while the mean for those who received text-based communication was 2661.333.

Previous research has indicated the essential nature of student engagement for online learning to be successful and for students to persist in an online course (Kahu, 2013; Pazzaglia et al., 2016; Pittaway, 2012; Tinto, 1997). Thus, examining student engagement and the mechanisms to improve engagement in an online course is necessary to the future of online learning. Despite the findings of previous research, which indicated a positive relationship between the use of asynchronous video and increased student engagement (Draus et al., 2014), the findings of the present study suggest that text-based communication increases student engagement more than asynchronous video communication. Zak (2015) also found that student engagement did not increase with the use of asynchronous video communication in an online course, despite its positive effect on students' sense of community. Analysis of the students quantitative and qualitative data indicated that while they appreciated the asynchronous video, it was of little consequence to their learning or learning behaviors, including engagement, within the course (Zak, 2015). Asynchronous video has been suggested as a potential method for increasing student engagement through humanization of the instructor in the online course (Glazier, 2016). The results of this study did not support these findings. The present study analyzed the use of asynchronous video as a means for increasing student engagement in an online classroom. While the data was statistically significant, the results indicated that the use of text-based communication improved student engagement more extensively based on both number and length of discussion board posts. 


\section{Summary}

The purpose of this quasi-experimental, quantitative design study was to examine the relationship between the independent variable of types of communication and the dependent variables of instructor social presence and student engagement. Using a MANOVA statistical analyses, the researcher was able to determine a statistical significance for the use of asynchronous video and student engagement, and no statistical significance for the use of asynchronous video and instructor social presence. Due to concerns about the sample size, and violations of the assumptions of the MANOVA, the researcher suggests considering the results cautiously. Significance was found in the number and length of discussion posts based on type of communication, though unexpectedly, the results indicated that text-based communication was more effective at improving student engagement than asynchronous video. No significance was found between the use of asynchronous video and instructor social presence.

Finding a statistical significance for student engagement is an important step in understanding the use of asynchronous video in an online classroom. These findings show that asynchronous video may not be as effective as text-based communication. The research does not support the relationship between asynchronous video, instructor social presence, and student engagement, which is alluded to in the literature. 


\section{Chapter 5: Implications, Recommendations and Conclusions}

Online education has grown exponentially over the last decade, with enrollments in online courses quickly outpacing enrollment in traditional face-to-face classes (Allen et al., 2016; Caruth \& Caruth, 2013). Concerns about student retention in online programs is an issue many higher education institutions have struggled to correct (Allen \& Seaman, 2014; Xu \& Jaggars, 2014). Students who feel isolated and lack the support of a classroom community tend to be more likely to drop out of online course than those students who feel connected to their classmates and instructors (Ali \& Smith, 2015; McMahon, 2013). Furthermore, student engagement, which is fostered through a sense of community, is also a predictor of student persistence and other academic outcomes, in online courses (Pazzaglia et al., 2016; Tinto, 1997).

Developing teaching andragogy that supports student engagement and fosters instructor social presence is necessary to achieve increased retention in online programs. An important component to the development of student engagement is the role of instructor social presence in setting up the online environment to be conducive to student success through integration of teaching presence and social presence (Bowers \& Kumar, 2015; Lowenthal, 2016). The present study focused on addressing the use of educational technology as a method for improving student engagement and the students' perceptions of instructor social presence, through asynchronous video. The specific problem of addressing student retention was investigated by studying how the type of communication (asynchronous video or text-based communication) affected student engagement and instructor social presence in an online, occupational therapy course.

Online education allows students to learn in a way that is more flexible with regard to time and space than the traditional classroom setting. Online learning requires students to be selfdirected, motivated and personally responsible for their educational experience in order to be successful (Xu \& Jaggars, 2014). An important component of student success in the online 
classroom is the student's willingness to engage in the learning process through affective, cognitive, and behavioral means. According to Kahu (2013) this includes the student's enthusiasm, interest, self-regulation, time and effort, and participation in the learning process. Significant to the development of student engagement is the role of the instructor and the importance of the interpersonal relationship between the instructor and student (Glazier, 2016; Ma et al., 2015; Phirangee et al., 2016). Instructor social presence has been investigated as a primary contributor to the progress of the instructor-student relationship, which is necessary for successful online teaching and learning (Lowenthal, 2016; Pollard et al., 2014). A combination of both teaching and social presence, instructor social presence describes the ability of the instructor to project themselves as a real person in the online environment (Richardson et al., 2015). The establishment of instructor social presence may lead to increased feelings of connection and increased student engagement in online courses (Bowers \& Kumar, 2015; Pollard et al., 2014). While quantitatively unfounded in the current literature, the assertion that instructor social presence leads to increased student engagement has been repeatedly suggested based on qualitative findings (Byrd, 2016; Glazier, 2016). Investigating the relationship between the development of student engagement and instructor social presence in a fully online course was a primary focus of the current study.

As online learning has matured in its use of various educational technology, resources to improve the student experience have been explored in the literature (Chen et al., 2010; Venkatesh, Croteau, \& Rabah, 2014). Many researchers have suggested that asynchronous video is an important tool for humanizing the online environment and increasing students' perceptions of instructor social presence (Borup et al., 2011, 2012, 2014; Glazier, 2016). Borup et al. (2014) indicated that qualitative analysis depicted a significant relationship between asynchronous video 
and instructor social presence, and that quantitative data analysis did not demonstrate significance. The researchers also concluded that the blended environment may have impacted the students' perceptions of instructor social presence regardless of the use of asynchronous video and that additional study of the use of asynchronous video for increasing student perceptions of instructor social presence should be conducted in a fully online environment (Borup et al., 2014).

The use of asynchronous video to improve student engagement has also been suggested, in the literature. The connection between asynchronous video and student engagement has been tenuous, with some researchers stating that asynchronous video does improve student engagement (Draus et al., 2014), and other researchers suggesting that no significant impact has been found (Zak, 2015). Draus et al. (2014) described an increase in student engagement, as measured by the number of student discussion posts, based on the increased use of asynchronous video in an online course. The researchers did not control for increased instructor involvement in the discussion boards, which could have impacted student participation and altered the findings of the study. The current study aimed to explore the use of asynchronous video for both enhancing students' perceptions of instructor social presence and student engagement in a fully online course, using qualitative methodology.

The purpose of this quasi-experimental, quantitative design study was to determine whether the independent variable of type of communication had a significant effect on the dependent variables of instructor social presence and student engagement. Although the present study builds on previous research, it is unique due to the focus on quantitative analysis, the deployment of the research in a fully online course, and the use of voluntary discussion boards as a means for measuring student engagement. Focusing on quantitative analysis in an online course 
is appropriate in order to help the target population of online learners succeed in online courses and improve student retention.

All data was collected through the host institution, the University of St. Augustine for Health Sciences, which has been in the process of converting many of its face-to-face courses to blended and fully online courses. The present study utilized two sections of an online foundational Masters of Occupational Therapy course in the spring of 2017. All participants voluntarily enrolled in one of the two sections of the course based on their program enrollment status as either a campus-based student or Flex-based student. The independent variable of type of communication had two levels: asynchronous video and text-based communication. The instructor generated twice weekly course announcements were individualized to each section of the course, and delivered using one of the two communication methods depending on the group. Group A (campus) received asynchronous video and Group B (Flex) received text-based communication. Students in each group were measured through the two dependent variables of student engagement and instructor social presence.

Student engagement data was collected by counting the number and length of discussion board posts in a voluntary discussion forum over 5 weeks of the course. Instructor social presence data was collected through an online Likert scale survey delivered towards the end of the course. The research procedures followed in the present study adhered to the standards for conducting research involving human subjects. Permission to utilize students from the University of St. Augustine, and IRB approval from the University of St. Augustine for Health Science, were gained prior to initiating the study. A Multivariate Analysis of Variance (MANOVA) statistical procedure was used to analyze the data. The purpose of this present study was to determine any effect the type of communication might have on students' perceptions of 
instructor social presence and student engagement in an online occupational therapy course. The implications, limitations, and contributions to the literature regarding the research questions are addressed in the following sections.

Implications

According to Allen et al. (2016), more than $25 \%$ of higher education students are enrolled in at least one online course. With an increasing number of students enrolling in online courses, developing teaching methodologies that support online learner success and retention is essential (Allen et al., 2016). Understanding the use of educational technology for improving student perceptions of instructor social presence and student engagement in an online classroom is important to the future of online teaching, and the ability of institutions to impact retention issues. Through qualitative means, research has shown that asynchronous video is an effective way to convey teacher immediacy behaviors, which increases instructor social presence and humanizes the online environment in a way that encourages online student engagement (Borup et al., 2014; Glazier, 2016; Mcdowell, 2011). Previous research has focused on studying the impact of asynchronous video on student engagement and instructor social presence separately. Research has alluded to a connection between the use of the two processes, through improvement in instructor social presence, though this assumption has not been examined (Borup et al., 2011; Glazier, 2016). The present study focused on exploring the impact of asynchronous video on student engagement and instructor social presence as potentially connected variables that may both be effected by the type of communication used in a fully online course.

Research Question 1: Does instructor use of asynchronous video change students' perceptions of instructor social presence in an online occupational therapy course? The first 
research question investigated the independent variable, type of communication, and the effect it had on the dependent variable, instructor social presence, in a fully online course. This question separates the present study from previous research because of its focus on an online course and the use of quantitative data to define an increase in instructor social presence (Borup et al., 2014).

The null hypothesis was not rejected for this research question because no statistically significant difference was found in the amount of student-perceived instructor social presence based on the type of communication students received in an online class. The findings show that there was no difference in students' perceptions of instructor social presence based on the use of asynchronous video communication. Understanding how instructors can best convey instructor social presence in an online classroom can be beneficial to the development of the instructorstudent relationship and the sense of classroom community, which leads to improved student engagement (Borup et al., 2014; Lowenthal, 2016; Pollard et al., 2014). It is relevant to show that asynchronous video was not more effective than text-based communication for conveying instructor social presence. Instructors and institutions adopt new educational technology to enhance teaching methodology and require a strong understanding of the implications of its use prior to implementation. The results of this study support the findings of previous research that has not found a significant difference in instructor social presence using asynchronous video, through quantitative data analysis (Borup et al., 2014). A limitation of the present study was not including qualitative collection or analysis of student comments to help further explore this complex relationship.

\section{Researcher Question 2: Does instructor use of asynchronous video change student} engagement in an online occupational therapy course? The second research question focused 
on how types of communication influenced the engagement in voluntary online discussion boards, which were measured by the number of discussion posts and the length of discussion posts. After the data analysis, the researcher concluded that there was a statistically significant difference in the amount of student engagement based on type of communication. The null hypothesis was rejected in the current study. Both the number of student posts and the length of student posts were statistically significant for this study $(p=.003, p=.012)$. The alternate hypothesis was supported because there was a difference in the number of student posts based on the use of asynchronous video versus text-based communication $(\mathrm{M}=.462, \mathrm{M}=4.333)$ and length of posts $(M=421.923, M=2661.333)$. Important to note is that those in the group who received text-based communication demonstrated more student engagement than those in the asynchronous video group for both number and length of posts.

Previous research has supported the use of asynchronous video for improving the rate of student engagement in online discussion forums (Draus et al., 2014). This study does not support this notion and actually establishes text-based communication as a more effective method for increasing student engagement. Draus et al. (2014) provided one of the only studies linking the use of asynchronous video to online student engagement through quantitative data. These researchers did indicate that the increased presence of the instructor in the discussion boards, through text-based communication, was not controlled for and this could have altered the results of the study. Zak (2015) indicated that asynchronous video did improve the development of a sense of community but did not impact student engagement in an online course. The current research found no significant difference in the use of asynchronous video and text-based communication, though the focus of the videos in the study were designed to deliver content and were not necessarily used to convey the presence of the instructor in the course. Glazier (2016) 
described the use of asynchronous video for increasing student engagement as a way to humanize the instructor through announcements in an online course. This researcher explained the importance of the development of instructor-student rapport as the main outcome of utilizing asynchronous video (Glazier, 2016). Garrison et al. (2005) stated that the development of rapport, or the simple interaction between instructors and students, was not sufficient to influence student learning behaviors which would include student engagement. The present study indicated that the visual and audio presence of the instructor in the form of asynchronous video was not as effective as the text-based communication provided to the students. Perhaps textbased communication was more efficient at providing the clear communication and instructions that students found most helpful in an online learning course, which led to increased engagement (Richardson et al., 2015; Sheridan \& Kelly, 2010).

Additional analysis of the correlation between individual items on the Instructor Social Presence survey and the type of communication used indicated that students in the text-based group perceived the instructor as "creating an attitude of sharing" (Pollard et al., 2014, p.9) more than students in the asynchronous video group. Though this difference in perception cannot be readily explained, the students' perceptions of the instructor and an attitude of sharing may help explain why a difference in student engagement was apparent. Students in the text-based group felt an increased attitude of sharing in the classroom community, which may have been manifested in their willingness to share their personal opinions and thoughts in the voluntary online discussion forums. The results of the present study do not support the results of previous studies which indicated either a positive relationship between asynchronous video and student engagement (Draus et al., 2014; Glazier, 2016), or no significant relationship between asynchronous video and student engagement (Zak, 2015). 
A limitation in the present study was an inherent difference between the two groups, which may have impacted the results of this study. Xu and Jaggars (2013) indicated that older students may be more adaptable to online technology and better suited for online learning. Given that the results of the current study indicated higher student engagement in the Flex course, which enrolls more non-traditional students, the results of this study may be based on the adaptability of the learner due to other demographic variables, and not the type of communication used in the classroom. The significant findings of increased student engagement using text-based communication is important for instructors in fully online courses so the proper type of communication may be used to positively influence student engagement.

\section{Limitations}

The present study focused on gathering data from one small, private institution which specializes in educating students in the health sciences. The focus was also on collecting and analyzing quantitative data that could measure the effectiveness of asynchronous video for increasing instructor social presence and student engagement in an online classroom. This study was conducted to help instructors and institutions deliver online content in an effective way, which may improve student engagement and student feelings of classroom community, to reduce attrition in online courses. Previous research has shown asynchronous video as an effective method for increasing students' perceptions of instructor social presence and student engagement in blended courses based on qualitative and mixed-method results (Borup et al., 2014; Draus et al., 2014; Glazier, 2016; Ma et al., 2015). Quantitative data supporting the use of asynchronous video in the online classroom is limited and does not reinforce qualitative findings or the assumptions researchers have made about the connection between asynchronous video, instructor social presence, and student engagement (Borup et al., 2014; Draus et al., 2014; Zak, 2015). 
Examining the relationship between these constructs from a quantitative perspective, in a fully online course, was unique to this study.

The present study experienced limitations in the equality of groups and sample size which may have impacted the results. The groups were pre-determined based on the enrollment of students in either the campus or Flex MOT programs. Campus students are typically more traditional, meaning they are younger and have limited obligations outside of school that require attention (Ortagus, 2017). These students are also expected to take part in a more traditional program that includes primarily face-to-face and blended learning environments, based on the description of the program prior to spring 2017 (University of St. Augustine, 2016a). Students in the Flex program are typically non-traditional students, or those who are older and have outside obligations such as work or family (Ortagus, 2017). These students were also aware that the Flex program utilized primarily online and blended courses throughout the program (University of St. Augustine, 2016a). Inherent differences between the groups of students may have impacted the results of the present study. Additionally, the sample size for the current study was small with a high rate of attrition from the campus group. More than $55 \%$ of the students from the campus group did not participate in the study after providing consent. One possible reason for the high attrition rate was the fact that the students in the campus group were taking more credits, on average, than the students in the Flex group. Campus students are automatically enrolled in 17 credit hours of courses in their first term, versus the Flex students who were enrolled in nine credits (University of St. Augustine, 2016a). The additional burden of other courses may have caused more students to stop participating in the study than anticipated. 


\section{Recommendations}

The present study examined the effect of asynchronous video on student perceptions of instructor social presence and student engagement in two sections of a fully online course. Independent from previous research, this study examined the three variables, asynchronous video, instructor social presence, and student engagement, as possibly interconnected constructs that may impact student learning and retention in online programs. The current research also utilized quantitative data only to determine if a relationship existed. Based on the results of the present study, the researcher has developed recommendations for future practice and research.

From the data analysis, and the finding that text-based communication was more effective than asynchronous video for improving student engagement, the researcher recommends that online instructors not expect asynchronous video to improve student engagement in an online course. The researcher also recommends that the use of twice weekly, text-based instructor announcements in an online course may facilitate student engagement in discussion forums and should be considered when delivering an online course. Since previous research has not established text-based communication as the more effective method of increasing student engagement, further research in this area is needed. Additionally, based on the findings of the present study, the researcher recommends that the use of asynchronous video does not increase student perceptions of instructor social presence and that online instructors may not find benefit in utilizing this medium to increase the instructor social presence in an online course. Based on previous research that showed no significant difference in instructor social presence through quantitative means, but did demonstrate a positive influence based on qualitative data (Borup et al., 2011, 2012, 2014), the researcher further recommends additional study on the use of asynchronous video to increase instructor social presence in a fully online course utilizing a mixed method design. 
While the intent of the current research was to examine the use of asynchronous video in a fully online course, the inherent differences between the two groups may have influenced the results and generalizability of the study to other populations. Therefore, additional study should be conducted using larger sample sizes, and accounting for demographic differences in the student population during analysis. Future research investigating the use of asynchronous video for increasing instructor social presence and student engagement is needed to determine how to best impact the variables that lead to student retention in online courses.

\section{Conclusions}

As more students and institutions turn to online learning as the platform for providing the educational experience, it is essential to understand the methods for improving student success and retention in these courses (Ali \& Smith, 2015; McMahon, 2013; Xu \& Jaggars, 2014). Allen et al. (2016) predicted an increase in student enrollment in online courses, even as the retention rates for online students continue to be an issue in many fields of study. Understanding the methods for increasing student retention and improving student outcomes is important for the future of online learning.

Based on previous research, student engagement is an essential component to creating a sense of community and reducing feelings of isolation, which often lead to online student attrition (Ali \& Smith, 2015; Bowers \& Kumar, 2015; McMahon, 2013). Improving student engagement can be challenging due to the complicated nature of the construct and the selfdirected nature of the online learning environment (Dixson, 2010; Kahu, 2013; Pittaway, 2012). One potential method for improving student engagement is the use of instructor social presence to create an instructor-student relationship and humanize the online course, so it is conducive to student participation and motivation (Bowers \& Kumar, 2015; Glazier, 2016; Kushnir \& Berry, 
2014; Phirangee et al., 2016). Through the instructor-student relationship, student learning behaviors can be shaped to help students be more successful in the online classroom (Pazzaglia et al., 2016; Tomas et al., 2015). Developing teaching methodology for enhancing instructor social presence and student engagement in an online course is important to online faculty and institutions (Allen et al., 2016; Xu \& Jaggars, 2014). The intent of the present study was to examine the use of asynchronous video to increase student engagement and instructor social presence in a fully online course.

Previous qualitative and mixed method research has concluded that asynchronous video may be a viable method for increasing instructor social presence and student engagement in blended or online classrooms (Borup et al., 2014; Draus et al., 2014; Glazier, 2016). Borup et al. (2014) indicated that asynchronous video was effective for increasing instructor social presence based on qualitative study, but demonstrated no significant difference through quantitative analysis. Draus et al. (2014) concluded that asynchronous video was more effective at increasing student engagement in an online course, but did not consider the increased instructor interaction that took place in the discussion boards of the asynchronous video group.

The present study, much like previous research, found no quantitative significant difference in instructor social presence based on the use of asynchronous video. Unlike previous studies, the present study found that text-based communication was more effective than asynchronous video for increasing student engagement in an online class. Additional investigation is necessary to determine whether asynchronous video can impact student perceptions of instructor social presence and student engagement in a fully online course. Based on the analysis of the instructor social presence items, it appears that the text-based group perceived that the instructor promoted an atmosphere of sharing more than the asynchronous 
video group. Additional investigation through mixed method analysis may provide insight about how types of communication in an online environment is perceived by students, and what factors affect students' perceptions of instructor social presence. The current study focused on how the type of communication may impact perceptions of instructor social presence, which is a combination of teaching presence and social presence. Additional investigation may include analysis of the impact of type of communication on perceived instructor social presence, social presence, and teaching presence, in concert with student engagement. Such an investigation may help determine whether asynchronous video can influence one area of the Community of Inquiry framework more than another, and how those interactions shape student engagement.

The results of the current study indicate that text-based communication may be the preferred method for increasing student engagement in voluntary discussion forums, in a fully online course. Due to limitations in the study, the results should be considered cautiously. Further investigation is needed to understand the unique results found in this research. Knowing how to utilize educational technology, such as asynchronous video, to enhance perceptions of instructor social presence and student engagement is important to the future of online learning. Utilizing an appropriate type of communication to enhance the instructor-student relationship and to improve student learning behaviors is important as online education enrollments grow and the demand for positive student outcomes increases (Ali \& Smith, 2015; Atchley et al., 2013). 


\section{References}

Ali, A., \& Smith, D. (2015). Issues in informing science and information technology comparing social isolation effects on students attrition in online versus face-to-face courses in computer literacy. Issues in Informing Science and Information Technology, 12, 11-20. Retrieved from http://iisit.org/Vol12/IISITv12p011-020Ali1784.pdf

Allen, I. E., \& Seaman, J. (2014). Grade Change: Tracking Online Education in the United States. Retrieved from http://www.utc.edu/learn/pdfs/online/sloanc-report-2014.pdf

Allen, I. E., Seaman, J., Poulin, R., \& Straut, T. T. (2016). Online report card: Tracking online education in the United States. Retrieved from http://onlinelearningsurvey.com/reports/onlinereportcard.pdf

Anderson, T., Rourke, L., Garrison, D. R., \& Archer, W. (2001). Assessing teaching presence in a computer conferencing context. Journal of Asynchronous Learning Network, 5(2), 1-17. Retrieved from http://auspace.athabascau.ca/bitstream/2149/725/1/assessing_teaching_presence.pdf

Angelino, L. M., Williams, F. K., \& Natvig, D. (2007). Strategies to engage online students and reduce attrition rates. The Journal of Educators Online, 4(2), 1-14. Retrieved from http://files.eric.ed.gov/fulltext/EJ907749.pdf

Arbaugh, J. B., Cleveland-Innes, M., Diaz, S. R., Garrison, D. R., Ice, P., Richardson, J. C., \& Swan, K. P. (2008). Developing a community of inquiry instrument: Testing a measure of the Community of Inquiry framework using a multi-institutional sample. Internet and Higher Education, 11(3-4), 133-136. https://doi.org/10.1016/j.iheduc.2008.06.003

Archer, W., \& Garrison, D. R. (2010). Distance education in the age of the internet. In C. E. Kasworm, A. D. Rose, \& J. M. Ross-Gordon (Eds.), Handbook of Adult and Continuing Education (pp. 317-326). Thousand Oaks, CA: SAGE Publications, Inc. 
Armellini, A., \& De Stefani, M. Social presence in the 21st century: An adjustment to the Community of Inquiry framework. British Journal of Educational Technology, 47(6), 1202-1216. https://doi.org/10.1111/bjet.12302

Atchley, T. W., Wingenbach, G., \& Akers, C. (2013). Comparison of course completion and student performance through online and traditional courses. The International Review of Research in Open and Distributed Learning, 14(4).

https://doi.org/http://www.irrodl.org/index.php/irrodl/article/view/1461/2627

Baker, C. (2010). The impact of instructor immediacy and presence for online student affective learning, cognition, and motivation. Journal of Educators Online, 7(1), 1-30. Retrieved from http://0search.ebscohost.com.library.regent.edu/login.aspx?direct=true \&db=eue $\& A N=48316167$

Blackley, S., \& Sheffield, R. (2015). Digital andragogy: A richer blend of initial teacher education in the 21st century. Issues in Educational Research, 25(4), 397-414.

Boone, H. N., \& Boone, D. A. (2012). Analyzing Likert Data. Journal of Extension, 50(2). Retrieved from https://www.joe.org/joe/2012april/tt2.php

Borup, J., Graham, C. R., \& Velasquez, A. (2011). The use of asynchronous video communication to improve instructor immediacy and social presence in a blended learning environment. In A. Kitchenham (Ed.), Blended learning across disciplines Models for implementation (pp. 38-57). Hershey, PA: IGI Global. https://doi.org/10.4018/978-160960-479-0.ch003

Borup, J., West, R. E., \& Graham, C. R. (2012). Improving online social presence through asynchronous video. Internet and Higher Education, 15(3), 195-203. https://doi.org/10.1016/j.iheduc.2011.11.001 
Borup, J., West, R. E., Thomas, R., \& Graham, C. (2014). Examninnig the impact of video feedback on instructor social presence in blended courses. International Review of Research in Open \& Distance Learning, 15(3), 1-15. https://doi.org/10.19173/irrodl.v15i3.1821

Bowers, J., \& Kumar, P. (2015). Students' perceptions of teaching and social presence: A comparitive analysis of face-to-face and online learning environments. International Journal of Web-Based Learning and Teaching Technologies, 10(1), 27-44. https://doi.org/10.4018/ijwltt.2015010103

Byrd, J. C. (2016). Understanding the online doctoral learning experience: Factors that contribute to students' sense of community. The Journal of Educators Online, 13(2), 1-34. Retrieved from http://files.eric.ed.gov/fulltext/EJ1106735.pdf

Caruth, G. D., \& Caruth, D. L. (2013). Distance education in the United States: From correspondence courses to the internet. Turkish Online Journal of Distance Education, 14(8), 141-149. Retrieved from http://files.eric.ed.gov/fulltext/EJ1013772.pdf

Chen, P.-S. D., Lambert, A. D., \& Guidry, K. R. (2010). Engaging online learners: The impact of web-based learning technology on college student engagement. Computers \& Education, 54, 1222-1232. https://doi.org/10.1016/j.compedu.2009.11.008

Chickering, A. W., \& Gamson, Z. F. (1987). Seven principles for good practice in undergraduate education. AAHE Bulletin, 39(7), 3-7. Retrieved from http://files.eric.ed.gov/fulltext/ED282491.pdf

Creswell, J. W. (2014). Educational research: Planning, conducting, and evaluating quantitative and qualitative research (4th ed.). Upper Saddle River, NJ: Pearson Education, Inc.

Dixson, M. D. (2010). Creating effective student engagement in online courses: What do students find engaging? Journal of the Scholarship of Teaching and Learning, 10(2), 1-13. 
Retrieved from http://josotl.indiana.edu

Dixson, M. D. (2015). Measuring student engagement in the online course : The Online Student Engagement Scale ( OSE ). Online Learning Journal, 19(4), 1-15. Retrieved from http://www.eric.ed.gov/contentdelivery/servlet/ERICServlet?accno=EJ1079585

Draus, P. J., Curran, M. J., \& Trempus, M. S. (2014). The influence of instructor-generated video content on student satisfaction with and engagement in asynchronous online classes. Journal of Online Learning \& Teaching, 10(2), 240-254. Retrieved from http://jolt.merlot.org/vol10no2/draus_0614.pdf

Estepp, C. M., \& Roberts, T. G. (2015). Teacher immediacy and professor/student rapport as predictors of motivationa and engagement. North American Colleges and Teachers of Agriculture, 59(2), 155-163. Retrieved from http://go.galegroup.com.prx-usa.lirn.net/

Estes, J. S. (2016). The pivotal role of faculty in online student engagment and retention. In C. Kyei-Blankson, L., Blankson, J., Ntuli, E., Agyeman (Ed.), Handbook of Research on Strategic Management of Interaction, Presence, and Participation in Online Courses (pp. 66-88). Hershey, PA: IGI Global.

Field, A. (2009). Discovering statistics using SPSS (3rd ed.). Thousand Oaks, CA: SAGE Publications, Inc.

Finch, H. (2005). Comparison of the performance of nonparametric and parametric MANOVA test statistics when assumptions are violated. Methodology, 1(1), 27-38. https://doi.org/10.1027/1614-1881.1.1.27

Garrison, D. R. (1997). Self-directed learning: Toward a comprehensive model. Adult Education Quarterly, 48(1), 18-33. https://doi.org/https://doi.org/10.1177/074171369704800103 Garrison, D. R. (2007). Online Community of Inquiry Review : Social, Cognitive , and Teaching 
Presence Issues. Journal of Asynchronous Learning Networks, 11(1), 61-72. https://doi.org/10.1128/JB.05513-11

Garrison, D. R., Anderson, T., \& Archer, W. (2010). The first decade of the community of inquiry framework: A retrospective. Internet and Higher Education, 13(1-2), 5-9. https://doi.org/10.1016/j.iheduc.2009.10.003

Garrison, Anderson, T., \& Archer, W. (2000). Critical inquiry in a text-based environment: Computer conferencing in higher education. The Internet and Higher Education, 2-3, 1-34. https://doi.org/10.1016/S1096-7516(00)00016-6

Glazier, R. A. (2016). Building rapport to improve retention and success in online classes building rapport to improve retention and success in online classes. Journal of Political Science Education, O(0), 1-20. https://doi.org/10.1080/15512169.2016.1155994

Graham, C. R., Woodfield, W., \& Buckley Harrison, J. (2013). A framework for institutional adoption and implementation of blended learning in higher education. The Internet and Higher Education, 18, 4-14. https://doi.org/10.1016/j.iheduc.2012.09.003

Griffiths, M. E., \& Graham, C. R. (2009). The potential of asynchrnonous video in online education. Distance Learning, 6(2), 13-22. Retrieved from http://immagic.com/eLibrary/ARCHIVES/GENERAL/JOURNALS/I090300J.pdf\#page=69

Gulati, S. (2008). Compulsory participation in online discussions: is this constructivism or normalisation of learning? Innovations in Education and Teaching International, 45(2), 183-192. https://doi.org/10.1080/14703290801950427

Handelsman, M. M., Briggs, W. L., Sullivan, N., \& Towler, A. (2005). A measure of college student course engagement. The Journal of Educational Research, 98(3), 184-191. https://doi.org/http://dx.doi.org/10.3200/JOER.98.3.184-192 
Hatcher, L. (2013). Advanced statistics in research: Reading, understanding, and writing up data anlaysis results. Saginaw, MI: Shadow Finch Media.

Heyman, E. (2010). Overcoming student retention issues in higher education online programs. Online Journal of Distance Learning Administration, 13(4). Retrieved from http://www.westga.edu/ distance/ojdla/winter134/heyman134.html

Ice, P., Curtis, R., Phillips, P., \& Wells, J. (2007). Using asynchronous audio feedback to enhance teaching presence and students' sense of community. Journal of Asynchronous Learning Networks, 11(2), 3-25. Retrieved from http://eric.ed.gov/?id=EJ842694

Kahu, E. R. (2013). Framing student engagement in higher education. Studies in Higher Education, 38(5), 758-773. https://doi.org/10.1080/03075079.2011.598505

King, S. B. (2014). Graduate student perceptions of the use of online course tools to support engagement. International Journal for the Scholarship of Teaching and Learning, 8(1), 120. https://doi.org/10.20429/ijsot1.2014.080105

Knowles, M. (1984). Andragogy in action: Applying modern principles of adult learning. San Fransisco, CA: Jossey-Bass.

Kushnir, L. P., \& Berry, K. C. (2014). Inside, outside, upside down: New directions in online teaching and learning. In International Conference e-Learning (pp. 133-140). Lisbon, Portugal: International Association for Development of the Information Society. Retrieved from http://eric.ed.gov/?id=ED557256

Ladyshewsky, R. K. (2013). Instructor presence in online courses and student satisfaction. International Journal for the Scholarship of Teaching and Learning, 7(1), 1-23. https://doi.org/10.20429/ijsotl.2013.070113

Lawson, M. A., \& Lawson, H. A. (2013). New conceptual frameworks for student engagement 
research, policy and practice. Review of Educational Research, 83(3), 432-479. https://doi.org/10.3102/0034654313480891

Lowenthal, P. R. (2016). A mixed methods examination of instructor social presence in accelerated online courses. In C. kyei-Blankson, L., Blankson, J., Ntuli, E., Agyeman (Ed.), Handbook of Research on Strategic Management of Interaction, Presence, and Participation in Online Courses (pp. 147-159). Hershey, PA: IGI Global. https://doi.org/10.4018/978-1-4666-9582-5.ch006

Ma, J., Han, X., Yang, J., \& Cheng, J. (2015). Examining the necessary condition for engagement in an online learning environment based on learning analytics approach: The role of the instructor. Internet and Higher Education, 24, 26-34. https://doi.org/10.1016/j.iheduc.2014.09.005

Mcdowell, J. (2011). Using asynchronous video to promote learner engagement through the enhancement of assessment and feedback. Retrieved from http://eprints.hud.ac.uk/10888/

McMahon, M. (2013). A study of the causes of attrition among adult on a fully online training course. Irish Journal of Academic Practice, 2(1), 1-26. Retrieved from http://arrow.dit.ie/ijap

Mehrabian, A. (1971). Silent Messages. Belmont, CA: Wadsworth Publishing.

Merriam, S. B. (2001). Andragogy and self-directed learning: Pillars of adult learning theory. New Directions of Adult and Continuing Education, 89, 3-13. https://doi.org/10.1002/ace.3 Mezirow, J. (1997). Transformative learning: Theory to practice. New Directions for Adult and Continuing Education, 74, 5-12. https://doi.org/10.1002/ace.7401

Moore, R. L. (2014). The importance of developing community in distance education courses. TechTrends, 58(2), 20-24. Retrieved from 
http://s3.amazonaws.com/academia.edu.documents/46094706/FINAL-TechTrends.pdf

National Survey of Student Engagement. (2016). Engagement insights: Survey findings on the quality of undergraduate education. Annual Results. Bloomington, IN. Retrieved from http://nsse.indiana.edu/NSSE_2016_Results/pdf/NSSE_2016_Annual_Results.pdf

O’Shea, S. E., Stone, C., \& Delahunty, J. (2015). "I "feel” like I am at university even though I am online". Exploring how students narrate their engagement with higher education institutions in an online learning environment. Distance Education, 1, 41-58. http://dx.doi.org/10.1080/01587919.2015.1019970

Oncu, S., \& Cakir, H. (2011). Research in online learning environments: Priorities and methodologies. Computers \& Education, 57, 1098-1108. https://doi.org/10.1016/j.compedu.2010.12.009

Ortagus, J. C. (2017). From the periphery to prominence: An examination of the changing profile of online students in American higher education. The Internet and Higher Education, 32, 47-57. https://doi.org/10.1016/j.iheduc.2016.09.002

Pazzaglia, A. M., Clements, M., Lavigne, H. J., \& Stafford, E. T. (2016). An analysis of student engagement patterns and online course outcomes in Wisconsin. Washington: DC. Retrieved from http://files.eric.ed.gov/fulltext/ED566960.pdf

Phirangee, K., Epp, C. D., \& Hewitt, J. (2016). Exploring the relationships between facilitation methods, students' sense of community, and their online behaviors. Online Learning, 20(2), 1-21. Retrieved from http://hdl.handle.net/1807/73603

Pittaway, S. (2012). Student and staff engagement : Developing an engagement framework in a faculty of education. Australian Journal of Teacher Education, 37(4), 37-47. Retrieved from http://files.eric.ed.gov/fulltext/EJ969532.pdf 
Poll, K., Widen, J., \& Weller, S. (2014). Six instructional best practices for online engagement. Journal of Online Doctoral Education, 1(1), 56-72. Retrieved from http://ecommons.luc.edu/cgi/viewcontent.cgi?article=1030\&context=english_facpubs

Pollard, H., Minor, M., \& Swanson, A. (2014). Instructor social presence within the Community of Inquiry framework and its impact on classroom community and the learning environment. Online Journal of Distance Learning. Retrieved from http://eric.ed.gov/?id=EJ1036782

Revere, L., \& Kovach, J. V. (2011). Online technologies for engaged learning: A meaningful synthesis for educators. Quarterly Review of Distance Education, 12(2), 113-124. Retrieved from http://search.proquest.com/openview/ee56bfc90cac37ad96a4f6be61918f02

Richardson, J. C., Besser, E., Koehler, A., Lim, J., \& Strait, M. (2016). Instructors' perceptions of instructor presence in online learning environments. International Review of Research in Open \& Distance Learning, 17(4), 1-23. https://doi.org/http://dx.doi.org/10.19173/irrodl.v17i4.2330

Richardson, J. C., Koehler, A. a, Besser, E. D., Caskurlu, S., Lim, J., \& Mueller, C. M. (2015). Conceptualizing and investigating instructor presence in online learning environments. International Review of Research in Open \& Distance Learning, 16(3), 256-297. https://doi.org/10.1080/01587919.2015.1055920

Rourke, L., Anderson, T., Garrison, D. R., \& Archer, W. (2007). Assessing social presence in asynchronous text-based computer conferencing. International Journal of E-Learning \& Distance Education, 14(2), 50-71. Retrieved from http://www.ijede.ca/index.php/jde/article/viewArticle/153/341

Rovai, A. P. (2002). Building sense of community at a distance. The International Review of 
Research in Open and Distributed Learning, 3(1), 1-16.

https://doi.org/http://dx.doi.org/10.19173/irrodl.v3i1.79

Shea, P., Hayes, S., Vickers, J., Gozza-Cohen, M., Uzuner, S., Mehta, R., ... Rangan, P. (2010).

A re-examination of the community of inquiry framework: Social network and content analysis. The Internet and Higher Education, 13, 10-21.

https://doi.org/10.1016/j.iheduc.2009.11.002

Sheridan, K., \& Kelly, M. a. (2010). The indicators of instructor presence that are important to students in online courses. Journal of Online Learning and Teaching, 6(4), 767-779.

Retrieved from http://search.proquest.com/openview/8427fc89315300df781345e6e3c56ba2

Short, J., Williams, E., \& Christie, B. (1976). The social psychology of telecommunications. London: John Wiley \& Sons, Ltd.

Swan, K., Garrison, D. R., \& Richardson, J. C. (2009). A constructivist approach to online learning: the Community of Inquiry framework. Information Technology and Constructivism in Higher Education: Progressive Learning Frameworks, 43-57. https://doi.org/10.4018/978-1-60566-654-9.ch004

Swan, K. P., Richardson, J. C., Ice, P., Garrison, R., Cleveland-Innes, M., \& Arbaugh, B. (2008). Validating a measurement tool of presence in online communities of inquiry. E-Mentor, 2(24), 1-12. Retrieved from https://www.researchgate.net/profile/D_Garrison/publication/265406073_Validating_a_Me asurement_Tool_of_Presence_in_Online_Communities_of_Inquiry/links/5429d3650cf277d 58e86ff71.pdf

Swan, K., \& Shih, L. F. (2005). On the nature and development of social presece in online discussions. Journal of Asynchronous Learning Networks, 9(3), 115-136. Retrieved from 
http://anitacrawley.net/Articles/Swan and Shih2005.pdf

Tichavsky, L. P., Hunt, A. N., Driscoll, A., Jicha, K., Tichavsky, L. P. ;, \& Hunt, A. N. ; (2015). \&quot;It' s just nice having a real teacher\&quot;: Student perceptions of online versus faceto-face instruction. International Journal for the Scholarship of Teaching and Learning, 9(2), 1-10. https://doi.org/10.20429/ijsotl.2015.090202

Tilley, B. P. (2014). What makes a student non-traditional? A comparison of students over and under age 25 in online, accelerated psychology courses. Psychology Learning and Teaching, 13(2), 95-106. https://doi.org/10.2304/plat.2014.13.2.95

Tinto, V. (1997). Classrooms as communities: Exploring the educational character of student persistence. Journal of Higher Education, 68(6). Retrieved from http://ic.galegroup.com.

Tomas, L., Lasen, M., Field, E., \& Skamp, K. (2015). Promoting online students' engagement and learning in science and sustainability preservice teacher education. Australian Journal of Teacher Education, 40(4011), 79-107. https://doi.org/10.14221/ajte.2015v40n11.5

Trochim, W. M. K., \& Donnelly, J. P. (2007). The research methods knowledge base (3rd ed.). Cincinnati, OH: Atomic Dog Publishing.

University of St. Augustine. (2016a). Catalog. St. Augustine: University of St. Augustine. Retrieved from www.usa.edu

University of St. Augustine. (2016b). Student Handbook. St. Augustine: University of St. Augustine. Retrieved from www.usa.edu

Venkatesh, V., Croteau, A. M., \& Rabah, J. (2014). Perceptions of effectiveness of instructional uses of technology in higher education in an era of web 2.0. Proceedings of the Annual Hawaii International Conference on System Sciences, 110-119.

https://doi.org/10.1109/HICSS.2014.22 
Weiss, R. E. (2000). Humanizing the online classroom. New Directions for Teaching and Learning, 2000(84), 47-51. Retrieved from http://www.acousticslab.org/dots_sample/module3/Weiss2000_HumanizingOnlineClass.pdf

Whiteside, A. L. (2015). Introducing the social presence model to explore online and blended learning experiences. Online Learning Journal, 19(2), 1-20. Retrieved from https://olj.onlinelearningconsortium.org/index.php/olj/article/viewFile/453/137

Xie, K., Durrington, V., \& Yen, L. L. (2011). Relationship between students' motivation and their participation in asynchronous online discussions. Journal of Online Learning and Teaching, 7(1), 1-17. Retrieved from http://jolt.merlot.org/vol7no1/xie_0311.htm

Xu, D., \& Jaggars, S. S. (2013). Adaptability to online learning: Differences across types of students and academic subject areas (Community College Research Center No. 54). New York.

Xu, D., \& Jaggars, S. S. (2014). Performance gaps between online and face-to-face courses: Differences across types of students and academic subject areas. The Journal of Higher Education, 85(5), 633-659. https://doi.org/10.1353/jhe.2014.0028

Zak, S. M. (2015). Exploring the effect of asynchronous video on student learning and engagement in music e-learning. Columbia University. Retrieved from www.proquest.com Zepke, N., Leach, L., \& Butler, P. (2010). Student engagement: What is it and what influences it? Teaching and Learning Research Initiative. Wellington, New Zealand. Retrieved from http://www.tlri.org.nz/sites/default/files/projects/9261-Introduction.pdf 


\section{Appendix A: Permission Granting Access to University Students and Materials}
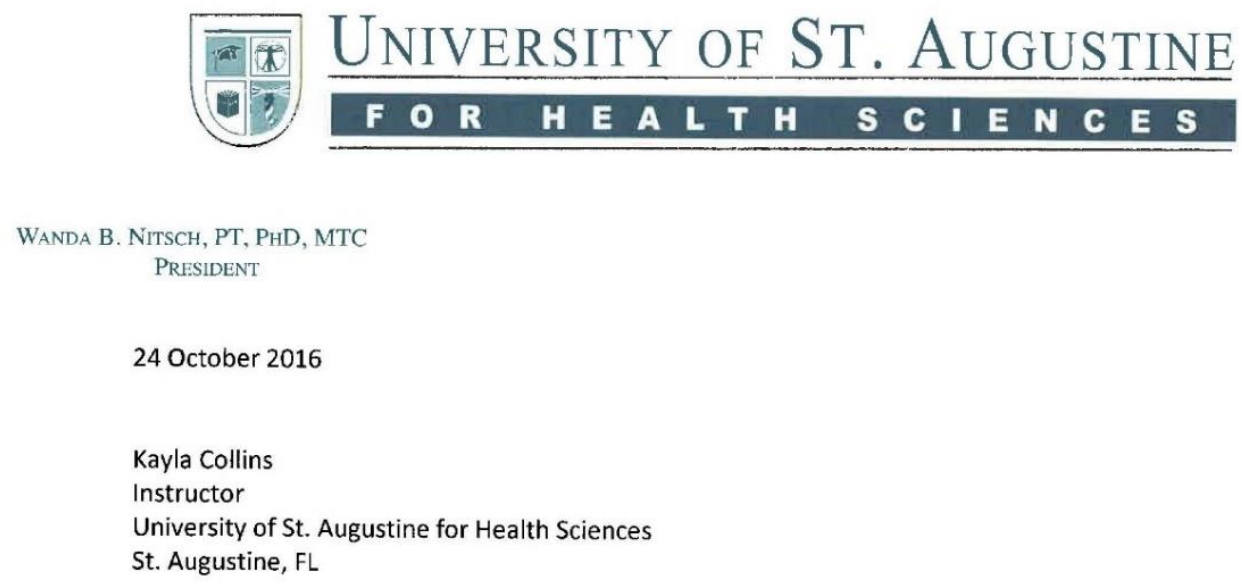

- Permission to conduct the study in two sections of the MOT's Domain of Occupational Therapy Course

- The use of a University owned laptop computer to collect and store data

- The use of the University's Survey Monkey account to distribute the instructor Social Presence Survey

- The use of the University's SPSS subscription to analyze data

You are granted permission to utilize these resources.

I wish you much success in your upcoming research project, and hope to learn for your results in the near future.

Sincerely,

Whada Nitoch, PT PhD

Wanda Nitsch, PT, PhD

President/Chief Academic Officer

\section{Appendix B: Instructor Social Presence Survey}

Instructor Social Presence Scale 
Directions: This survey should take approximately 10 minutes of your time. Thinking only about the primary instructor, Kayla Collins, and the course Domain of Occupational Therapy, rate the following items using a 5-point scale: $1=$ strongly disagree, $2=$ disagree, $3=$ neutral, $4=$ agree, $5=$ strongly agree. Thank you for taking part in this survey.

1. My instructor is a caring person with the students.

2. My instructor is a "real person" with the students.

3. My instructor is NOT professional with the students.

4. My instructor is humble with the students.

5. My instructor does NOT provide open communications.

6. My instructor does NOT create unity.

7. My instructor creates an attitude of sharing.

8. My instructor creates an attitude of group encouragement.

9. My instructor does NOT draw the class together.

10. My instructor grades my performance fairly. 


\section{Appendix C: University of St. Augustine Institutional Review Board Approval}

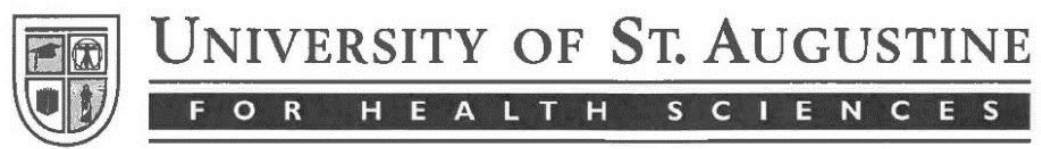

November 14, 2016

Kayla Collins, MOT, OT/L

1 University Blvd

St Augustine FL 32086

RE: IRB\# OT-1116-249 “Asynchronous Video and the Development of Instructor Social Presence and Student Engagement"

Dear Ms. Collins:

A member of the Institutional Review Board (IRB), responsible for the review of research involving human subjects, has reviewed and expedited your research proposal. Approval for the project will be for one year, starting November 14, 2016.

This approval is granted with the understanding that no changes may be made in the procedures to be followed until after such modifications have been submitted to the IRB for review and approval.

Any unanticipated problems involving risks to human subjects or serious adverse effects must be promptly reported to the IRB. Please include the IRB number assigned above on all documents related to this research.

Prior to the expiration of this approval, you will receive notification of the need for updated information to be used for the project's continuing review.

Should you complete this research project prior to the annual renewal date, please notify the IRB.

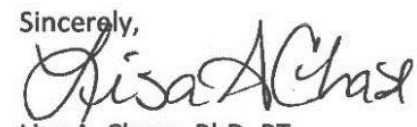

Lisa A. Chase, PhD, PT

Chair, IRB

\section{Cc: S. Groff \\ C. Mathena}




\section{Appendix D: Weekly Announcement Structural Outline}

The following outline for the first and second announcement of the week will be followed for each week's announcements in both sections of the course. The layout is based on research discussing the construct of instructor social presence and the attributes an instructor displays to enhance instructor social presence such as using the students' names, providing organization and structure, setting expectations, and showing concern for the students (Borup et al., 2014;

Lowenthal, 2016; Richardson et al., 2016)

The first interaction each week (text or video) will include:

- Instructor greeting

- Summary of content or assignments completed since the last announcement.

- Clarification of any questions, concerns, or issues since last announcement.

- Summary of content to be worked on and goals until next announcement.

- Salutation and reminder to participate in voluntary discussion.

The second interaction each week (text or video) will include:

- Instructor greeting

- Acknowledgment of any student achievements or recognition of exemplary work since the last announcement.

- Provision of additional resources, an example, or anecdote to support content.

- Summary of content to be worked on and goals until next unit announcement.

- Salutation and reminder to participate in voluntary discussion. 